\title{
Uncertainty handling in Fault Tree Based Risk Assessment: state of the art and future perspectives
}

\author{
Mohammad Yazdia, Sohag Kabir ${ }^{\mathrm{b}}$, Martin Walker ${ }^{\mathrm{b}}$ \\ ${ }^{a}$ Universidade de Lisboa, Lisbon, Portugal

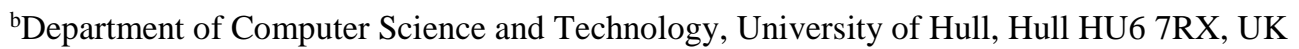

\begin{abstract}
Risk assessment methods have been widely used in various industries, and they play a significant role in improving the safety performance of systems. However, the outcomes of risk assessment approaches are subject to uncertainty and ambiguity due to the complexity and variability of system behaviour, scarcity of quantitative data about different system parameters, and human involvement in the analysis, operation, and decision-making processes. The implications for improving system safety are slowly being recognised; however, research on uncertainty handling during both qualitative and quantitative risk assessment procedures is a growing field. This paper presents a review of the state of the art in this field, focusing on uncertainty handling in fault tree analysis (FTA) based risk assessment. Theoretical contributions, aleatory uncertainty, epistemic uncertainty, and integration of both epistemic and aleatory uncertainty handling in the scientific and technical literature are carefully reviewed. The emphasis is on highlighting how assessors can handle uncertainty based on the available evidence as an input to FTA.
\end{abstract}

Keywords: Process safety, Uncertainty, Fault Tree Analysis, Risk Assessment, Bayesian theorem, Fuzzy set theory, Evidence theory.

\section{Introduction}

Uncertainty is an unavoidable part of any risk assessment technique, especially in probabilistic methods where uncertainty is a key part of the risk description. Risk is often defined as the combination of the probability of an uncertain, undesired outcome and the severity of that that outcome [1]. The term uncertainty expresses doubt, e.g., in the early design stages, an analyst may be uncertain about the failure rate of a new or a partially defined component. Moreover, uncertainty conveys lack of knowledge, e.g. we are very likely to know a chemical is toxic, but less likely to know what the effects might be if released in low concentrations into the environment.

The term uncertainty is applied in different ways in different fields, such as engineering, philosophy, science, and economics. Uncertainty is defined by the U.S. National Research Council as the "lack or incompleteness of information. Quantitative uncertainty assessment attempts to analyze and describe the degree to which a calculated value may differ from the true value; it sometimes uses probability distributions. Uncertainty depends on the quality, quantity, and relevance of data and on the reliability and relevance of models and assumptions" [2]. 
Numerous studies have been performed using mathematical models to examine uncertainty in the outcomes of quantitative risk assessment techniques. Uncertainty is often an integral part of these models, since making deterministic predictions regarding the future is essentially impossible. Instead, probabilistic data - often based on past experience - is used to model assumptions and predict future events. For example, the likelihood of failure of an engineering system may be modelled on the basis of the failure rates of its constituent components. In such cases, natural variability or randomness forces us to use probabilistic models to account for uncertainty regarding the outcome.

There are two main perceptions of uncertainty distinguished in a risk assessment procedure: (i) uncertainty related to physical mutability, and (ii) uncertainty related to the limitations on the knowledge of the system experts. The first category is the objectivity, which is commonly known as "aleatory uncertainty". It describes the uncertainty inherent in the random behaviour of many physical processes, such as the unpredictability of weather conditions and the occurrence of specific hardware failures due to wear and tear. Aleatory uncertainty can also be known as accidental uncertainty, characteristic uncertainty, and intolerable and unbearable uncertainty. This type of uncertainty is perceived when the same experiment is re-run under the same circumstances, yet different outcomes are obtained each time. Some degree of objective uncertainty is inevitable and can never be fully removed from a model; at best it can only be reduced. The second category is uncertainty related to the lack of knowledge or subjectivity, commonly known as "epistemic uncertainty". It is associated with the indecisiveness, ambiguity or fuzziness regarding the quality of a risk assessment technique. This type of uncertainty can be decreased as time passes and decision makers gain more knowledge.

Ferson and Ginzburg [3] provide an example to illustrate the differences between aleatory and epistemic uncertainties. As part of an extinction risk assessment for an endangered species of owl, different questions were posed, each exemplifying different forms of uncertainty. For example, the question "Do mortality mechanisms change from season to season?" represents the aleatory uncertainty with respect to the underlying variability of the situation being investigated. Since the seasonal weather and its effect on the owls is unpredictable, there is inherent uncertainty in determining the owls' mortality rate. In this case the uncertainty is due to the temporal variability the data changing over time - but it can equally be due to any other form of variability, e.g. spatial (how the data varies from location to location) or population-based (how the data varies from one individual to the next). On the other hand, the question "What is the number of owls present in the forest?" represents the epistemic uncertainty arising from the fact that we do not have perfect and complete information about the situation being studied: although there is a fixed and definite number of owls in the forest at a given moment of time, we do not necessarily know what that number is (because of the difficulty in tracking every owl in the forest). However, unlike the aleatory uncertainty, we can reduce the epistemic uncertainty here through additional study, e.g. by use of improved owl population tracking mechanisms.

Among the different probabilistic risk assessment (PRA) methods, FTA is the most-widely used approach for system safety and reliability evaluation. Using FTA it is possible to determine the probability of any undesired events, also known as top event, given the probability of the basic events, which are the lowest-level event causes. 
Therefore, it is necessary to quantify the failure probability of each basic event to be able to measure the probability of the top event. Criticality of the basic events can also be determined by calculating their relative contributions to the occurrence of the top event. The credibility of the results of the FTA-based risk assessment could be undermined due to the presence of the above-mentioned uncertainties. For instance, due to the lack of knowledge about the system under study, uncertainties, as imprecision and incompleteness, can be present in the parameters (e.g. failure rate data) used in the FTA. At the same time, the complexity of systems and lack of knowledge about the behaviour of the system often lead to simplification of assumptions during analysis. For instance, FTA assumes that events are independent, which is often an unrealistic assumption and it introduces uncertainties in the data and the modelling when using FTA. Moreover, in FTA, since the logical structure of fault trees (use of AND/OR gates) is specified by humans, there is a possibility of introducing structural error leading to model uncertainty. All these uncertainties can propagate from the lower level of the fault tree to the top level of the tree. Therefore, to improve the credibility of the results of FTA, uncertainties are required to be handled. The issue of uncertainty in FTA has not gone unnoticed and several methodologies have been proposed to address this issue in many different ways. Approaches that are used to handle uncertainty in FTA include, but not limited to, fuzzy set theory, evidence theory, Bayesian network, etc. Fuzzy set theory has been widely used to handle data uncertainty FTA and reviews of fuzzy set-based FTA is available in $[4,5]$. Other approaches such as Bayesian networks, evidence theory, and combination of multiple approaches to handle uncertainty in FTA are not reviewed in the past. This paper aims to provide a review of different approaches for uncertainty handling in FTA-based risk assessment. Although the primary focus of this paper is to review the advancements in uncertainty handling in fault tree based risk assessment, other closely related approaches that handles aleatory and/or epistemic uncertainty have also been reviewed briefly. For instance, generic fundamental and theoretical contributions towards uncertainty analysis is also reviewed. For brevity, the literature related to fuzzy FTA that are reviewed in [4,5] are excluded in this paper. The review of the uncertainty handling approaches presented in this paper shows the context in which each technique may be more appropriate and highlights the overall potential usefulness of them in addressing uncertainty in risk assessment.

The rest of this paper is structured as follows. In section 2, the review methodology used in this paper is explained. Theoretical contributions are then reported in section 3. Methodological and experimental contributions related to epistemic uncertainty handling in probabilistic risk assessments are covered in section 4 . Section 5 reports on advancements in handling aleatory uncertainty. Section 6 focuses on works which integrate both epistemic and aleatory uncertainty. Finally, discussion and concluding remarks are provided in section 7 , concentrating on the effectiveness and efficiency of the different types of approaches.

\section{The review methodology}

In conventional indexing systems, including Web of Science and Scopus, risk assessment and uncertainty are not reflected as a specific category. Instead, contributions connected with risk assessment are characteristically recorded under "mathematics", "social sciences" or "engineering". Therefore, common queries of those systems using expressions like "uncertainty", and "risk assessment" return many results covering a broad range of domains. Thus, 
an additional review procedure has been applied, concentrating on particular journals publishing studies on risk assessment approaches, quantitative and qualitative risk assessment, the foundations of risk assessment, and uncertainty handling in risk assessment techniques. To identify the relevant journals, a proper procedure was engaged as explained in [6] based on the five keywords "risk", "risk analysis", "risk assessment", "risk management", and "safety". Additionally, an online journal ranking tool SJR (https://www.scimagojr.com/) was utilized to recognize appropriate and associated journals using the keywords "risk assessment" and "uncertainty" in the title of the journal. Figure 1 represents the flow chart of the framework adopted for the review process.

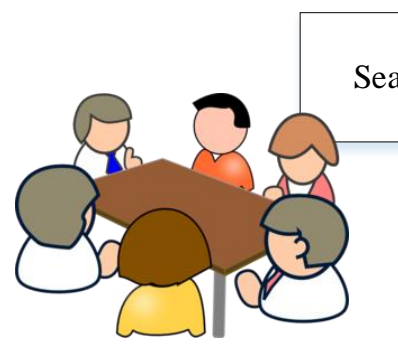

- Web of Science

- Scopus

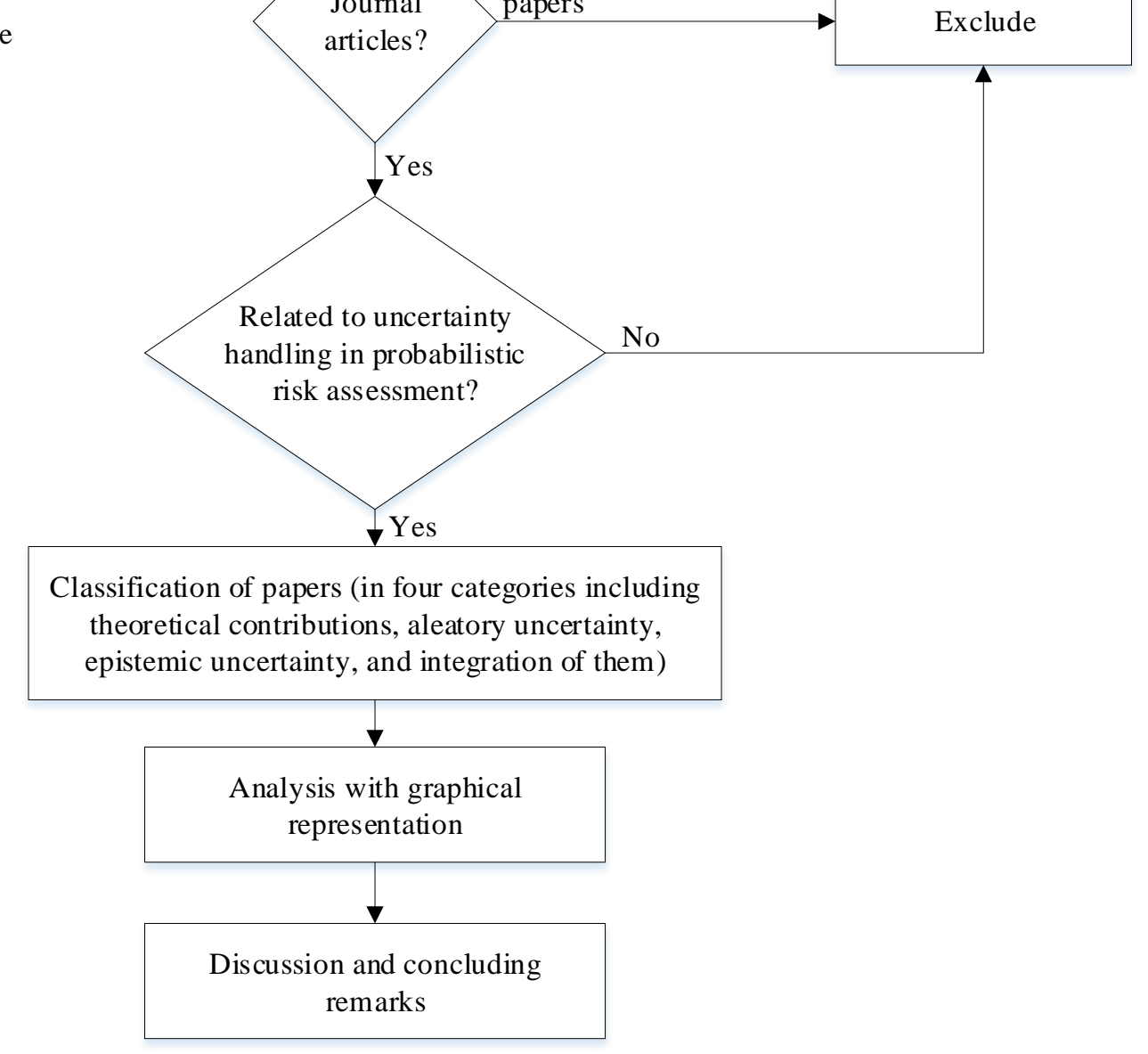

Figure 1. Flow chart of review methodology

The review was completed in January 2019, thus later publications are not included. Papers chosen for review were chosen using the following search expression: Publication Name = "full title of the journal name", (e.g., "Process 
Safety and Environmental Protection"), Document Type = "article", Topic = "risk assessment" AND "Uncertainty". Since "fault tree analysis" is the main probabilistic risk assessment technique being focused upon, the reviewed publications were classified in four categories. The initial category covered theoretical contributions, including the foundation of uncertainty in risk assessment and how uncertainty can be determined from a theoretical idea. The second category covered methodological and experimental contributions, representing works discussing the methods for epistemic uncertainty handling in fault tree analysis. The third category covered papers discussing aleatory uncertainty handling in risk assessment. Finally, the fourth category focuses on works which address an integration of both uncertainties handling in FTA. These four categories are explored in turn by the following four sections of this paper.

\section{Theoretical and fundamental contributions}

This section discusses the meaning of uncertainty based on theoretical and fundamental contributions, focusing specifically on the use of uncertainty in probabilistic risk assessment methods. Uncertainty is a key issue in any risk assessment technique [7]. Uncertainty is a typical expression in routine conversation, where it can mean different things in different contexts. However, for risk assessment techniques, the meaning of uncertainty is still a matter for discussion [8]. Based on an overview, uncertainty in typical risk assessment techniques can be divided into three categories, including consequences, probabilities, and human judgment. In some applications uncertainty and ambiguity are treated as similar concepts. Therefore, we can define two types of uncertainty related to the consequences of an unexpected event: interpretative and normative [9]. The latter refers to the different perspectives related to the tolerance of risk. Interpretative uncertainty refers to the variability in interpreting assessment outputs, e.g. due to decision makers processing of risk analysis results based on their own perspective and assumptions, such as whether a given consequence is harmful or not.

The third category of uncertainty refers to the lack of certainty in probabilistic assessment. The quality of information, weights of evidence, or source of reliability data in the risk assessment are all examples [10]. Basili [11] and Dubois [12] used some risk assessment techniques to illustrate this issue. Another version of this concept relates uncertainty to impreciseness in subjective expressions, e.g. ambiguity in the description of rare events [13]. In addition, non-probabilistic approaches have been extensively developed, such as fuzzy logic and possibility theory $[14,15]$, which are explained in later sections.

The last conception of uncertainty is related to human judgment, which describes the definition of probability in expert judgments, and uncertainty in the processing of information. Catrinu and Nordgård [16] state that uncertainty in a risk assessment procedure reflects the impression in human judgment regarding the preferences, values, and attitudes to risk, which can arise because of lack of sufficient understanding of problems, modelling assumptions, and so on. In addition, Richter and Koch [17] studied the role of safety culture on companies' interpretation and handling of risks and accidents. 
In theory, aleatory uncertainty cannot be reduced, while epistemic uncertainty can be reduced once more knowledge and information is available. However, many types of uncertainty were categorized as aleatory in the past but are now considered as epistemic. This fact means that the categorizing and classification of uncertainty has no fixed border [18]. In this regard, some scholars take the position that most uncertainty is epistemic $[19,20]$.

Three further categories of uncertainty - model, parameter, and completeness uncertainty — can be produced as a result of a risk analysis. However, there is no exact borderline to distinguish between them. Accordingly, any effort to handle uncertainty within each type may affect the others. Jin et al. [21] indicated that using multi-parameter distribution in place of an eventual distribution can decrease the uncertainty in some types of model, but on the other hand more parameter uncertainty may be produced.

Completeness uncertainty is associated with the overall risk assessment quality, its main purposes and domain, and the method by which its analyses are achieved. In completeness uncertainty, uncertainty may be further distinguished as recognized and unrecognized completeness uncertainty. The first refers to the factors that are completely recognized, but deliberately not included. The reason for an exception can be lack of sufficient understanding in its operating setting, cost or time restrictions, absence of information in order to assist the models, or lack of capability in utilizing the models. Thus, recognized uncertainty represents assumptions and simplifications related to costs, accessible resources, capabilities of analysis, and the information and knowledge about the operating environment and the system.

The next form of uncertainty, model uncertainty, is based on the fact that any model, whether mathematical, theoretical, or conceptual, will inevitably be only a simplistic representation of reality. Model uncertainty is intended to signify different models including stochastic models for system input, structural models of the system, spreading models, human behaviour models, accident models, etc. [22]. Deterministic and probabilistic are two key forms of this type of uncertainty and both are used in a risk assessment procedure. Deterministic models are typically considered to depict physical phenomena, e.g. pressure build up and physical influence. In contrast, life distribution of a component and wind direction can be considered as probabilistic models.

Finally, parameter uncertainty is linked to the uncertainty of parameter values commonly used in quantitative analyses. Such parameters can include failure rates for the different types of equipment as well as several failure modes, intervals between tests, probabilities of human error, effects of influencing factors, and frequencies of natural data.

In the rest of this section, some of the contributions to the fundamental understanding of uncertainty in risk assessment techniques are discussed.

In one of the earliest studies, Bari and Park [23] characterized uncertainty of data for probabilistic risk assessment (PRA) techniques. They proposed an approach according to the provided information and maximum entropy theory for dealing with uncertainty under certain circumstances. In 1996, RESS had a specific issue related to uncertainty in 
risk and reliability titled "Treatment of Aleatory and Epistemic Uncertainty- Volume 54, Issues 2-3". Published within were a number of attempts devoted to uncertainty modelling. As an example, Parry [24] characterized the uncertainty in PRA of complex systems such as chemical process plants and nuclear plants. He distinguished between aleatory and epistemic uncertainty using a simple example in order to recognize the importance of interpretation of the results of a PRA. Zio and Apostolakis [25] proposed a mathematical formulation for the handling of model uncertainty which represented enough capability to provide valuable understanding and organized direction to the expert judgment elicitation process. However, they stated that the approach relies on a clear understanding about the differences between aleatory and epistemic uncertainty. Paté-Cornell [26] examined six levels of analytical completeness in uncertainty handling in PRA and the possibility of transferring experience between the fields of application. This paper described the methods of treatment based on both deterministic and probabilistic uncertainties and also the different viewpoints that shape these assessments. In the same issue of RESS, Winkler [27] discussed the uncertainty in PRA at two different levels: a basic level and a practical level. At a basic level, uncertainty is just uncertainty and at this level, any attempt to make a distinction between the types of uncertainty can be questionable. At the second level, the distinctions between different types of uncertainties are guided by significant modeling subjects like as structure modeling, probability assessment, and sensitivity analysis.

Two years later, Renn [28] explained the role of risk perception with consideration of uncertainty handling for risk management. Morgan [29] provided the commentary and description of uncertainty analysis in risk assessment techniques. Murphy [30] commented on three laws proposed by Hattis [31] on risk assessment, including (i) "application of standard statistical data to a single data only a trivial proportion of the overall uncertainty in the parameter value", (ii) "any estimate of the uncertainty of a parameter value will always itself be more uncertain than the estimate of the parameter value", and (iii) "uncertainty in the uncertainty". Carrington and Bolger [32] discussed the topic as uncertainty and risk assessment. Firstly, they answered three important questions: "why is uncertainty part of risk assessment?", "why uncertainty is usually omitted?", and "why it is important to give uncertainty special notice?". Then a brief description of communication of uncertainty and computation of uncertainty was explained.

In 1999, Reckhow [33] discussed the importance of risk assessment techniques and uncertainty for improving environmental decision making. Furthermore, the number of lessons that decision makers could learn from risk assessment according to the uncertainty was explained. In the next decade, Reid [34] described the perceptions of confidence level and risk regarding the epistemological foundation of risk assessment and the uncertainty related to the approximation and description of risks. Flage and Aven [35] suggested an alternative method according to uncertainty and risk description, because decision making under uncertainty is the significant characteristic of project, safety, and uncertainty management. Their proposed approach made use of risk assessment and economic optimization tools such as the predictable net present value, but recognize the need for a comprehensive risk management procedure which extends outside the evaluation. Aven and Renn [36] discussed the role of qualitative risk assessment (QRA) due to risk and uncertainty characterization, and define suitable risk management options which specially emphasize the risk of terrorism. In a similar manner, Jones-Lee and Aven [37] discussed the task of civic cost-benefit assessment in societal decision making with respect to considerable uncertainties. Cooke [38] 
introduced a set of conundrums in relation to uncertainty factors in the integrated risk information system (IRIS) database. In another study, Cooke [39] discussed that using an improper methodology or even more unmethodological use of uncertain data will not be able to handle and contribute to the rational consensus. The five principles, including reproducibility, accountability, empirical control, neutrality, and fairness reported in his study represented an attempt to formulate a uniform guideline for using uncertain data in decision-making science. Recently, a comprehensive review [40] has been done to highlight the overall potential productivity of available methods in handling and managing the uncertainties in subjective safety and reliability engineering techniques. It simply concluded that merely an integration of methods could properly deal with the aforementioned principles. Aven [41] described different ways of defining and describing risk. Probability as the conventional perspective in engineering communities is highlighted; however, the study is also discussed that the given definitions and standpoints are excessively narrow. Thus, the probability component of the risk conception has to be substituted with uncertainty. In addition, by dealing with probability in such a limited way, uncertainty concepts can be easily ignored and shortened. Aven [42] also addressed both types of uncertainty as a requirement for PRA to handle variability. In another study, Markowski et al. [43] explained the sources of uncertainties in risk assessment of process safety areas. They signified that the important subjects in risk assessment outputs in different process safety applications are both uncertainties of input data and simulation models.

In 2011, Aven contributed to uncertainty handling in risk assessment techniques in five different papers. These contributions include drawing attention to the need for a proper risk perspective for resilience engineering [44]; introducing several types of uncertainties in the framework of the protective values [45]; recommending some ideas to improve the methodology and practice of selective critique of risk assessment based on uncertainty issues [46]; arguing that ISO 31000 failed in different approaches to produce reliable and expressive definitions of several key concept of uncertainty in risk assessment techniques [47]; and recognizing whether the analysts' or the experts' uncertainty assessments should be reported by risk assessment techniques [48]. In [49], Aven reviewed the definitions of risk-related concepts including the concept of uncertainty.

In 2013, Aven had made further contributions to the field of uncertainty analysis in risk assessment. Firstly, they discussed how the concept of risk with respect to numerous performers can affect risk communication related to risk assessment and risk management procedures [50]. A framework was proposed in [51] to better understand risk assessment and uncertainty according to four key issues: data, information, knowledge, and wisdom. Aven also explained how decision makers can cope with deep uncertainties, known probabilities, and correct models in risk assessment and risk management procedures [52]. Another study had introduced the practical implications of new risk perspectives, because many arguments have been widely made for the adoption of certain new types of risk perspective [53]. A novel method is introduced for uncertainty handling in the risk assessment technique which is applicable to a tunnel project [54].

The foundation issues in PRA as two key steps are introduced and discussed in [55] which highlights (i) reviewing and deliberating the current situations, and (ii) recognizing how to best advance in the future to progress the risk 
correction in the required direction. A new approach was introduced for treating model uncertainties for QRA in [56]. The approach follows the theoretical outline where a distinction is made between model error, model prediction, and model output uncertainty. Aven also discussed the implication of the black swans theory to the practice and foundation of risk assessment techniques in different contexts, including (i) unknown unknowns, (ii) unknown knowns, and (iii) events that are judged to have an insignificant occurrence probability [55,57,58]. Black swan theory was further discussed in [59]. In the paper, the authors provided a short communication to represent the restriction of black swan concepts to unknown unknowns.

Aven and Ylönen implemented a new risk perspective in order to give decision makers better insights about information, lack of information, and risk dimension [60]. A methodological comparison has been made for risk assessment under deep uncertainties using an ordinary example to show how the variances of each method is linked to the conventional risk assessment procedure [61], [62].

As can be seen from above mentioned reviews, the concepts of risk assessment based on uncertainty are welldefined and numerous developments have been made to cope with any available methodological shortcomings. Rather than the idea, it is time to shift the focus forward onto risk management using diverse approaches like adaptive risk management and robustness and resilience management. In this regard, risk management can be useful outside of the conventional risk assessment techniques. In addition to such methods that are available in the literature, QRA highlights signals and warnings such as deviations in assumption and potential concerns about the system.

\section{Methodological and empirical contributions to epistemic uncertainty handling}

As mentioned earlier, epistemic uncertainty is produced by knowledge deficits and in principle may be eliminated when decision makers can obtain proper knowledge about the object of study. It should be noted that there is no fixed border between epistemic and aleatory uncertainty. However, many studies found it useful to categorize uncertainty, as described earlier, and accordingly it is possible to identify appropriate solution technique to deal with the uncertainty. The main purpose of distinguishing between epistemic and aleatory uncertainties is that in mathematical terms it is much more correct [63]. In other words, combining epistemic and aleatory uncertainties means that a decision maker will not be able to see how much of the whole uncertainty comes from each of them. There are two available basic concepts: frequency-based and Bayesian. For frequency-based approaches, including statistical and fuzzy-based approaches, the idea of probability is defined as a restricting occurrence rate and can be applied if a decision maker could recognize an independent sample in a studied population; whereas Bayesian thoughts define probability as the degree of belief. Furthermore, supporting information includes statistical data, physical models, as well as experts' opinions [26]. The three strategies most commonly used to deal with epistemic uncertainty are presented as follows. 


\subsection{Subjective uncertainty handling using probability distribution}

During risk assessment, the failure behaviour of the system is often explained using different probability distributions. Lognormal distribution is a probability distribution widely used for this purpose. However, normal distributions are also useful in order to compute the basic event (BE) probability in FTA. In one study [39], it was illustrated that if an expert estimated the failure probabilities for at least 14 of the 39 components, then the distribution of outcomes in the corresponding experiment can be approximated with a normal distribution.

In some applications, the nature of the quantities whose distributions are assessed may be such as to suggest a particular class of probability distributions. This specific implementation presupposes that the experts' distributions are approximately normal; however, the idea may be applied to any class of distributions determined by two parameters. The study preferred to break the elicitation down into two steps: (1) the employed expert indicates a best estimate of the failure frequency in question in subjective way; and (2) he/she indicates "how certain" one is of the best estimate to obtain confidence level. Additionally, there was a preference for qualitative as well as quantitative elicitation procedures. The elicitation was broken down into two steps in a similar way: (1) the expert is asked for his/her median estimation of the failure frequency in question (his/her answer is high); and (2) the expert is asked how surprised he/she would be if the true value turned out to be higher by a factor of 10 or more, which reflects the probability that the true value should exceed the median by a factor of 10 or more.

In other words, it is assumed there is a probability density $p(x, y)$ giving the probability density that the true value is $x$, that the expert estimates this value as $y$ with standard deviation $\sigma$ through all BEs. The expert may be subjected to various biases, but in the simplest case he/she is unbiased. In this case, Cooke [39] assumed that if the true value is $x$ and the expert gives standard deviation $\sigma$, then the probability that he estimates $x$ as $y, p(y \mid x, \sigma)$ is the normal distribution with mean $x$ and standard deviation $\sigma$ :

$$
p(y \mid x, \sigma)=\left(2 \pi \sigma^{2}\right)^{-2} e^{-\left(\frac{1}{2}\right)\left[\frac{y-x}{\sigma}\right]^{2}}
$$

Thus, it seems reasonable to say this: if an unbiased expert's subjective distribution is normal having mean as $y$ and standard deviation as $\sigma$, with $y$ and $\sigma$ fixed, for a large number of failure frequencies, then if the true values for these frequencies were examined, they will indeed be normally distributed having mean as $y$ and standard deviation as $\sigma$ [64]. For such an expert:

$$
p(x \mid y, \sigma)=\left(2 \pi \sigma^{2}\right)^{-2} e^{-\left(\frac{1}{2}\right)\left[\frac{x-y}{\sigma}\right]^{2}}
$$

The normal density depends only on the square distance to the mean and the standard deviation, hence: $p(y \mid x, \sigma)=$ $p(x \mid y, \sigma)$. The authors could not find any attempt which has been made to compute the failure rate of basic events in a typical FTA using subjective elicitation. 


\subsection{Subjective uncertainty handling using fuzzy logic based approaches}

Fuzzy set theory was proposed by Zadeh as an alternative to the conventional probability theory which was recognized as unsuitable for representing all types of uncertainties [65]. In this concept, it is possible to describe linguistic terms as fuzzy numbers and it has enough capability to be assumed as an extension of the traditional probability theory due to its ability to represent imprecise values using continuous membership functions such as triangular and trapezoidal fuzzy numbers $[66,67]$.

In the literature, there are many studies stating that fuzzy logic is founded on the concept of partial membership degree in a numerical set. This membership is typically described as membership function and is belongs to interval one and zero (see Figure 2). In order to obtain more details about the concept of fuzzy logic one can refer to [68][69].

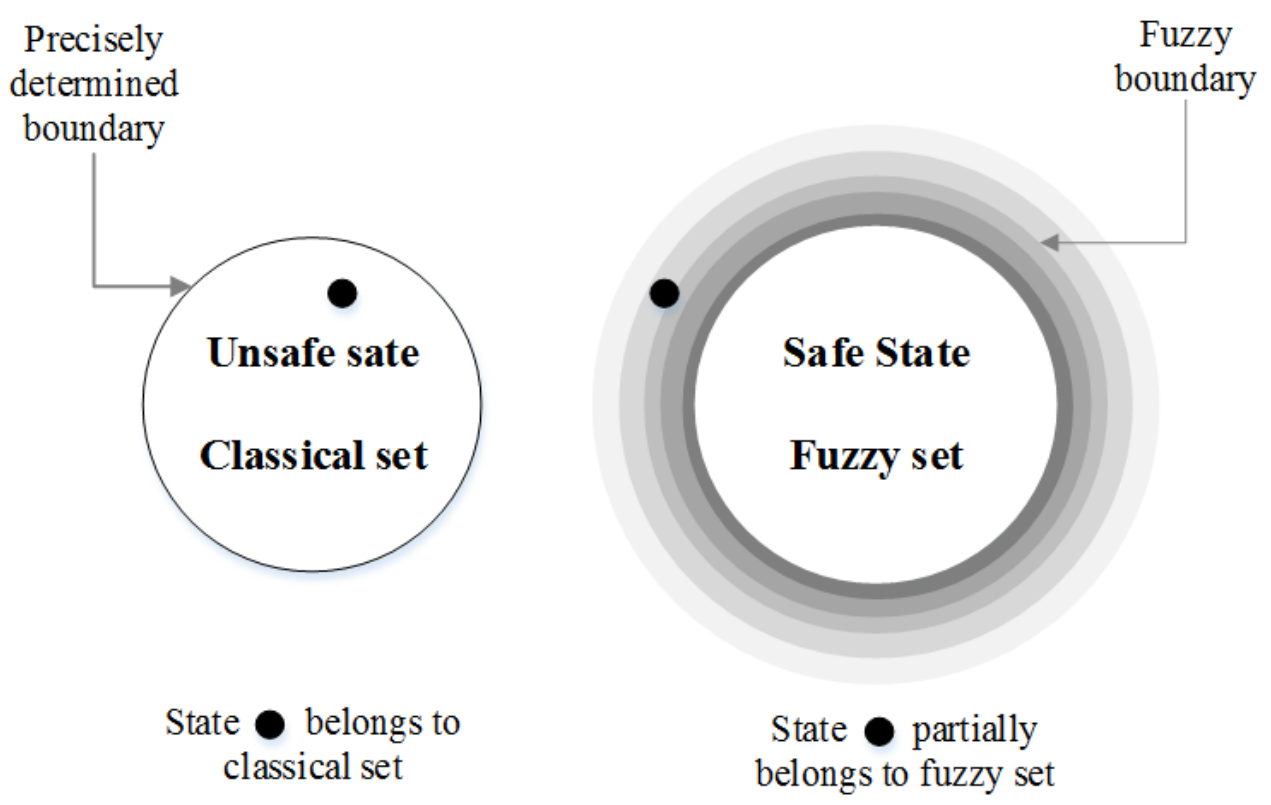

Figure 2. Convectional set and fuzzy set for safe and unsafe state (adopted from [68,70,71])

For example, a triangular fuzzy number illustrated in Figure 3 is the simple shape and accordingly shows the uncertainty in the possibility estimation of a basic event in typical FTA. The fuzzy vector $A=\left(P_{L}, P_{m}, P_{U}\right)$ signifies the lower, most likely, and the upper boundary, respectively. By engaging Equation (4), the membership degree of confidence can be estimated using defuzzification methods (e.g., centre of area method) in order to better deal with uncertainty. 


$$
\mu_{A}(x)=\left\{\begin{array}{cc}
0, & x<P_{L} \\
\frac{x-P_{L}}{P_{m}-P_{L}}, & P_{L} \leq x \leq P_{m} \\
\frac{P_{U}-x}{P_{U}-P_{m}}, & P_{m} \leq x \leq P_{U} \\
0, & x>P_{U}
\end{array}\right\}
$$

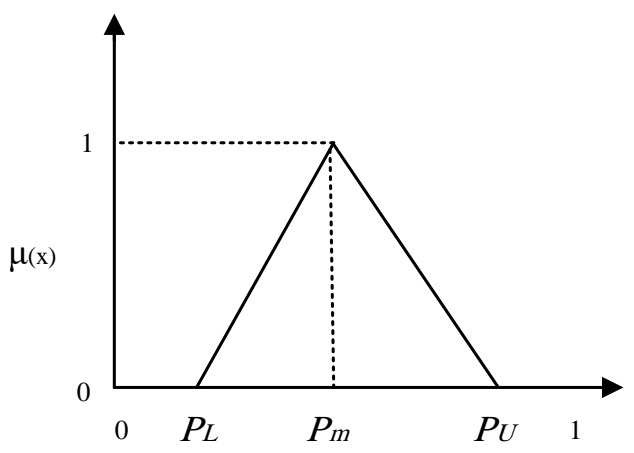

Figure 3. Triangular fuzzy number representing the estimation of possibility for an input event (like as BE)

$X^{*}=\frac{\int \mu_{i}(x) x d x}{\int \mu_{i}(x) d x}$

where $X^{*}$ means that the defuzzified output, $\mu_{A}(x)$ is denoted as a membership function, and $x$ is considered the output variable.

Fuzzy logic can handle subjective uncertainty in different ways during the risk assessment procedure. The first one is the subjective elicitation process, which has the same concept as the lognormal distribution method. It means that each employed expert expresses their opinion about the possibility of occurrence of the BEs in a FT in the form of qualitative terms. Subsequently, the qualitative terms are transferred into a set of fuzzy numbers. If a group of experts is used for the eliciting process, an aggregation procedure is applied in the fuzzy environment. Then, a defuzzification method is used to reach to the crisp value. However, this crisp value is based on possibility; thus, using Onisawa's equation the possibility can be transferred to the probability as follows $[72,73]$ :

$P=\left\{\begin{array}{ll}1 / 10^{K} & , C P \neq 0 \\ 0 & , C P=0\end{array} \quad, \quad K=\left[\left(\frac{1}{C P}-1\right)\right]^{1 / 3} \times 2.301\right.$

where probability of an input event is denoted by $P$, and crisp possibility is identified by $C P$.

In the second method, the probability of each BE (which may be obtained objectively or using reliability data from the handbook like as OREDA) is converted to the set of triangular fuzzy numbers with three different confidence, such as $25 \%, 50 \%$, and $75 \%$. This confidence selection is based on the type of study and experts' opinion. According to this change, the probability of TE is computed and behaviour of the system can be easily analysed in different confidence levels. 
Fuzzy modelling or fuzzy IF-THEN rules are another way to handle uncertainty for input variables like BEs. The basic structure of fuzzy modelling is illustrated in Figure 4 and is made of the following components: (i) the fuzzifier decomposes a reliability system (basic events as the input variables) with crisp numbers and converts the crisp numbers into a fuzzy set number; (ii) the inference and reading engine of the fuzzy modelling converts input fuzzy sets, based on knowledge, into fuzzy set numbers. Accordingly, "if-then-else" rules are implemented based on decision makers' opinions (for risk index and consequences probability); (iii) the defuzzifier provides an averaging and weighting process from all of the separated fuzzy rules for each variable.

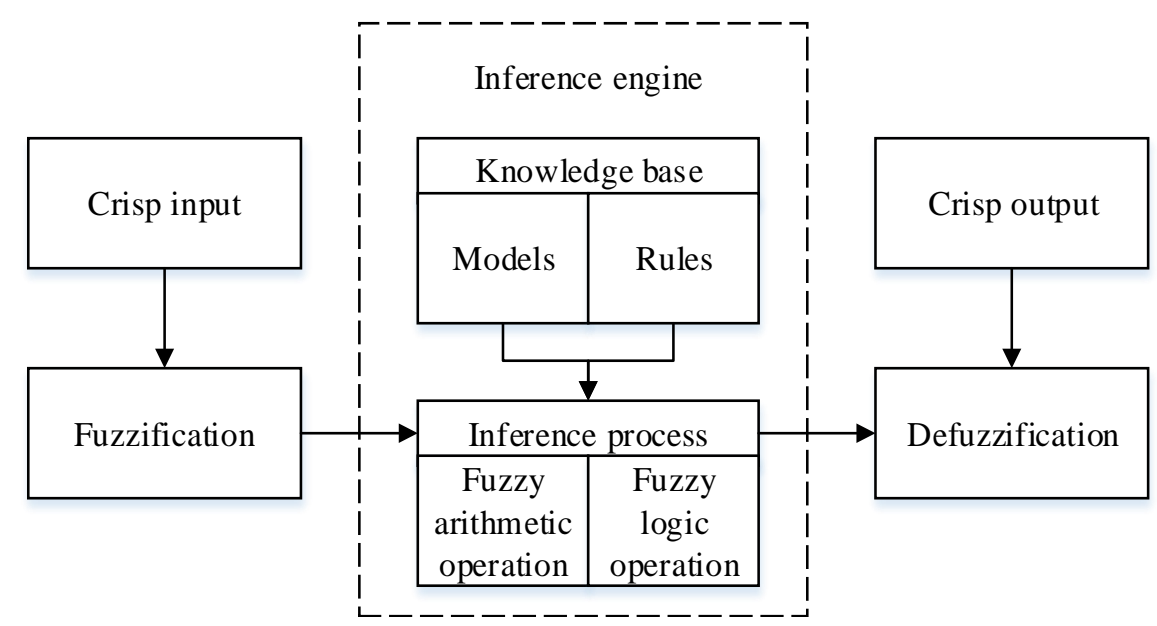

Figure 4. The framework of a common fuzzy modelling system

\subsection{Subjective uncertainty handling using Bayesian network}

In the literature, it is stated that Bayesian networks (BNs) have high flexibility compared to FTs, and a FT can be substituted by a BN in a risk assessment procedure [74]. Bayesian networks are common in machine learning, statistics, artificial intelligence, and risk assessment [75]. To create the corresponding Bayesian network of a FT, as illustrated in Figure 5, all elements in a typical FT are converted into the corresponding Bayesian network in which the nodes represent variables, Conditional Probability Tables (CPTs) assigned to the nodes numerically represent conditional dependencies, and arcs signify direct causal relationships between the linked nodes. For each intermediate node as well as each leaf node, a CPT is assigned. CPTs demonstrate how intermediate nodes are linked to preceding intermediate or root nodes [76].

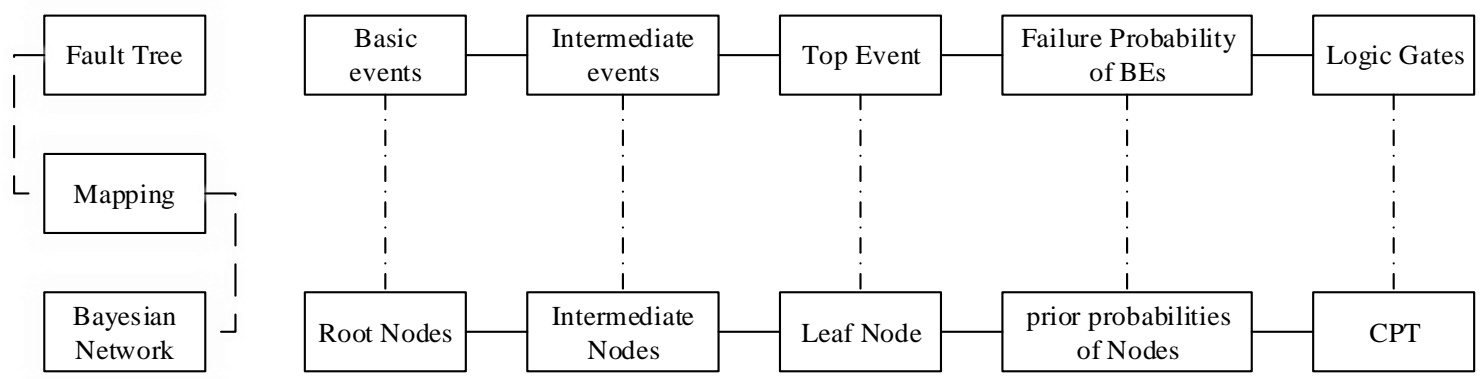

Figure 5. Converting a typical FT into the corresponding Bayesian network 
Assuming the conditional dependencies of variables, Bayesian network illustrates the distribution of joint probability as $P(U)$ :

$$
P(U)=\prod_{i=1}^{n-1} P\left(X_{i} \mid X_{i+1}, \ldots X_{n}\right)
$$

where $U=\left\{X_{1}, X_{2}, \ldots, X_{n}\right\}$ and $X_{i+1}$ is the parent of $X_{i}$. Accordingly, the probability of $X_{i}$ can be calculated as:

$$
P\left(X_{i}\right)=\sum_{U \backslash X_{i}} P(U)
$$

The key advantage of Bayesian networks is in the updating probability mechanism. This ability is usually based on expert knowledge or the extra information which becomes accessible in the process lifecycle, including incidents, near misses, accidents, mishaps, etc. With respect to Bayes theorem, Bayesian networks can be used to update the prior probability of an event [77-80]. The updated or posterior probabilities that decrease the uncertainty and reach much more realistic input for each basic event can be calculated as follows:

$$
P(U \mid E)=\frac{P(U \cap E)}{P(E)}=\frac{P(U \cap E)}{\Sigma_{U} P(U \cap E)}
$$

In order to get more details one can refer to [81-83].

\subsection{Analysis of epistemic uncertainty handling contributions}

From the prior discussion on epistemic uncertainty handling, the terms "fuzziness in FTA" can be further realized according to the following points of view. At first, fuzziness is defined as multi-dimensional reasoning in the FFTA which formulated in the interval zero and one. Table 1 summarizes the epistemic uncertainty contributions used in cited studies. After understanding the fuzziness in FTA, as mentioned earlier the interference mechanisms are classified according to three main strategies:

- A: Probability distribution

- B: Fuzzy logic-based

1. Elicitation process

2. Fuzzy confidence selection

3. Fuzzy modelling or fuzzy IF-THEN rules

- C: Bayesian network

The last column of Table 1 indicates uncertainty handling strategies of three above mentioned types. Figure 6 displays the main industrial sectors from where the case studies were selected to illustrate the epistemic uncertainty handling process in risk analysis or accident modelling analysis based on FTA methods. As can be seen, most of studies have been undertaken in the chemical process industry. 


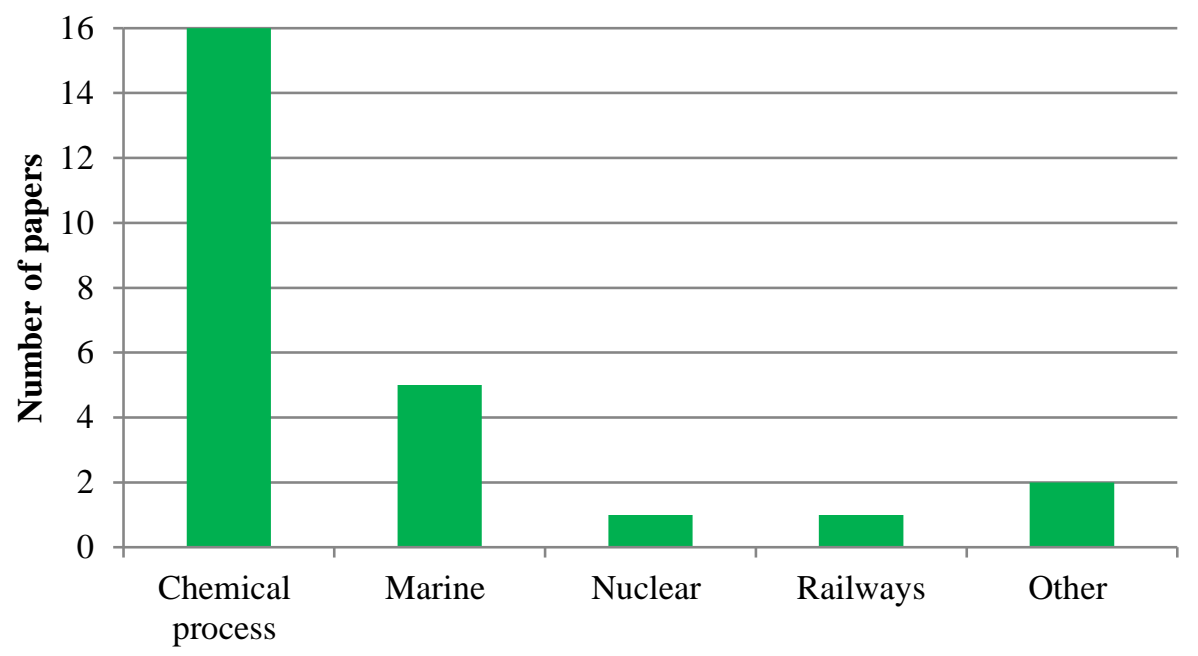

The fields of published papers

Figure 6. Number of papers on subjective uncertainty handling category of FTA in the various industrial sectors

Table 1. Subjective FTA in various industrial sectors

\begin{tabular}{|c|c|c|c|c|}
\hline Reference & $\begin{array}{l}\text { Industrial } \\
\text { sectors }\end{array}$ & $\begin{array}{l}\text { Application fields } \\
\text { (failure) }\end{array}$ & Highlights & Strategy \\
\hline $\begin{array}{l}\text { Markowski et al. } \\
\text { [84] }\end{array}$ & $\begin{array}{l}\text { Chemical } \\
\text { process }\end{array}$ & $\begin{array}{l}\text { Isobutane storage } \\
\text { tank (rupture of } \\
\text { tank) }\end{array}$ & $\begin{array}{l}\text { All input variables are substituted } \\
\text { with fuzzy numbers; after utilizing } \\
\text { fuzzy arithmetic process, the } \\
\text { probability of TE is then computed. }\end{array}$ & B. 2 \\
\hline Ferdous et al. [67] & $\begin{array}{l}\text { Chemical } \\
\text { process }\end{array}$ & $\begin{array}{l}\text { Activated carbon } \\
\text { filter safeguard } \\
\text { system (fail to } \\
\text { capture agent) }\end{array}$ & $\begin{array}{l}\text { Proposed an approach for a fuzzy } \\
\text { based using computer and fault tree } \\
\text { tools. }\end{array}$ & B. 2 \\
\hline Celik et al. [85] & Marine & $\begin{array}{l}\text { Shipping accident } \\
\text { (break down in } \\
\text { steam generation } \\
\text { system) }\end{array}$ & $\begin{array}{l}\text { Proposed integration of FFTA into a } \\
\text { shipping accident investigation } \\
(\mathrm{SAI})\end{array}$ & B.1 \\
\hline Mechri et al. [86] & $\begin{array}{l}\text { Chemical } \\
\text { process }\end{array}$ & $\begin{array}{l}\text { Safety } \\
\text { instrumented } \\
\text { system (SIS) (SIS } \\
\text { failure) }\end{array}$ & $\begin{array}{l}\text { Assessing the performance of SIS } \\
\text { with consideration of CCF. } \\
\text { Accepting decision makers to share } \\
\text { their opinions about uncertainty of } \\
\text { CCF values. }\end{array}$ & B. 2 \\
\hline $\begin{array}{l}\text { Mentes and } \\
\text { Helvacioglu [87] }\end{array}$ & Marine & $\begin{array}{l}\text { Spread mooring } \\
\text { system (damage to } \\
\text { cargo line) }\end{array}$ & $\begin{array}{l}\text { Proposed a methodology integrating } \\
\text { the effects of human errors and } \\
\text { operational failures in fuzzy }\end{array}$ & B. 2 \\
\hline
\end{tabular}




\begin{tabular}{|c|c|c|c|c|}
\hline & & & environment. & \\
\hline Shahriar et al. [88] & $\begin{array}{l}\text { Chemical } \\
\text { process }\end{array}$ & $\begin{array}{l}\text { Oil and gas } \\
\text { pipelines } \\
\text { release) }\end{array}$ & $\begin{array}{l}\text { Explored both subjective } \\
\text { uncertainty and interdependencies } \\
\text { among BEs. }\end{array}$ & B.1 \\
\hline $\begin{array}{l}\text { Aqlan and Mustafa } \\
\text { Ali [89] }\end{array}$ & $\begin{array}{l}\text { Chemical } \\
\text { process }\end{array}$ & $\begin{array}{l}\text { Manufacturing } \\
\text { decorative paints } \\
\text { (non-confirming } \\
\text { product) }\end{array}$ & $\begin{array}{l}\text { Introduced an approach for risk } \\
\text { analysis of a lean manufacturing } \\
\text { system using FFTA in one part. }\end{array}$ & B.1 \\
\hline Shi et al. [90] & $\begin{array}{l}\text { Chemical } \\
\text { process }\end{array}$ & $\begin{array}{l}\text { Oil tank (fire and } \\
\text { explosion) }\end{array}$ & $\begin{array}{l}\text { Proposed a methodology based on } \\
\text { FFTA which was improved by } \\
\text { AHP. }\end{array}$ & B.1 \\
\hline Chen [91] & Other & $\begin{array}{l}\text { Hoisting operation } \\
\text { (product damage) }\end{array}$ & $\begin{array}{l}\text { Hazard analysis of man-machine- } \\
\text { environment system is improved by } \\
\text { engaging a fuzzy causal model. }\end{array}$ & B.2 \\
\hline Omidvari et al. [92] & $\begin{array}{l}\text { Chemical } \\
\text { process }\end{array}$ & $\begin{array}{l}\text { Distillation tower } \\
\text { unit in a process } \\
\text { plant (reactor } \\
\text { failure) }\end{array}$ & $\begin{array}{l}\text { Application of fuzzy logic is } \\
\text { utilized to obtain the subjective } \\
\text { opinions of expert for each } \mathrm{BE} \text { and } \\
\text { computing the probability of TE. }\end{array}$ & B.1 \\
\hline Martorell et al. [93] & Nuclear & $\begin{array}{l}\text { Accumulator } \\
\text { system (failure to } \\
\text { inject from } \\
\text { accumulator) }\end{array}$ & $\begin{array}{l}\text { Proposed a method for assessment } \\
\text { of risk impacts using FTA based on } \\
\text { different confidence level of } \\
\text { probability of BEs. }\end{array}$ & - \\
\hline Lavasani et al. [94] & Marine & $\begin{array}{l}\text { Permanently } \\
\text { abandoned } \\
\text { offshore oil and } \\
\text { natural X-mast } \\
\text { tree. (leakage from } \\
\text { permanently } \\
\text { abandoned } \\
\text { offshore well) }\end{array}$ & $\begin{array}{l}\text { The proposed model focuses on risk } \\
\text { assessment of leakage in a typical } \\
\text { offshore well using an extension of } \\
\text { FFTA. }\end{array}$ & B.1 \\
\hline Ramzali et al. [95] & Marine & $\begin{array}{l}\text { Offshore drilling } \\
\text { system (failure of } \\
\text { operator) }\end{array}$ & $\begin{array}{l}\text { The proposed model used fuzzy set } \\
\text { theory to combine experts' } \\
\text { knowledge as an input probability } \\
\text { for FTA. }\end{array}$ & B.1 \\
\hline Lavasani et al. [96] & $\begin{array}{l}\text { Chemical } \\
\text { process }\end{array}$ & $\begin{array}{l}\text { Deethanizer unit in } \\
\text { a petrochemical } \\
\text { company }\end{array}$ & $\begin{array}{l}\text { The proposed model used fuzzy set } \\
\text { theory to combine experts' } \\
\text { knowledge as an input probability }\end{array}$ & B.1 \\
\hline
\end{tabular}




\begin{tabular}{|c|c|c|c|c|}
\hline & & $\begin{array}{l}\text { (Deethanizer } \\
\text { failure) }\end{array}$ & for FTA. & \\
\hline Duan et al. [97] & $\begin{array}{l}\text { Chemical } \\
\text { process }\end{array}$ & $\begin{array}{l}\text { Cryogenic liquid } \\
\text { Hydrogen filling } \\
\text { system (leakage } \\
\text { from process) }\end{array}$ & $\begin{array}{l}\text { Proposed a model to estimate the } \\
\text { risk of identified hazards according } \\
\text { to risk matrix. FFTA is used for } \\
\text { handling the likelihood factor of } \\
\text { risk matrix in this regards. }\end{array}$ & B.1 \\
\hline $\begin{array}{l}\text { Ahn and Chang } \\
\text { [98] }\end{array}$ & $\begin{array}{l}\text { Chemical } \\
\text { process }\end{array}$ & $\begin{array}{l}\text { LNG drum } \\
\text { segment (failure of } \\
\text { drum) }\end{array}$ & $\begin{array}{l}\text { Proposed a model to calculate risks } \\
\text { according to the ratio obtained from } \\
\text { variables of an event using fuzzy } \\
\text { modelling system. }\end{array}$ & B. 3 \\
\hline Yan et al. [99] & Other & $\begin{array}{l}\text { Biomass } \\
\text { Gasification } \\
\text { (leakage gas) }\end{array}$ & $\begin{array}{l}\text { Proposed a model to compute the } \\
\text { probability of TE based on fuzzy } \\
\text { probability. } \\
\text { BN is used for mapping FT and } \\
\text { considering the dependency } \\
\text { uncertainty between BE. }\end{array}$ & B. $1, \mathrm{C}$ \\
\hline Wang et al. [100] & $\begin{array}{l}\text { Chemical } \\
\text { process }\end{array}$ & $\begin{array}{l}\text { HIPPS (High } \\
\text { integrity pressure } \\
\text { protection system, } \\
\text { failure of HIPPS) }\end{array}$ & $\begin{array}{l}\text { Proposed a hybrid approach } \\
\text { engaging fuzzy set theory which } \\
\text { constructs a perfect judgment } \\
\text { reliance by giving perception into } \\
\text { the uncertainties. }\end{array}$ & B. 2 \\
\hline $\begin{array}{l}\text { Mohsendokht } \\
\text { [101] }\end{array}$ & $\begin{array}{l}\text { Chemical } \\
\text { process }\end{array}$ & $\begin{array}{l}U F_{6} \text { production } \\
\text { line }\left(U F_{6} \text { release }\right)\end{array}$ & $\begin{array}{l}\text { The proposed model used fuzzy set } \\
\text { theory to obtain probability of each } \\
\text { basic event failure as input to the } \\
\text { probability calculation of } U F_{6} \\
\text { release. }\end{array}$ & B. 1 \\
\hline Sahin [102] & Marine & $\begin{array}{l}\text { Offshore } \\
\text { production } \\
\text { technology } \\
\text { (offshore platform } \\
\text { collapse) }\end{array}$ & $\begin{array}{l}\text { Proposed a framework to control } \\
\text { consistency linked with the } \\
\text { consistency of employed experts by } \\
\text { prioritization straightforward fuzzy } \\
\text { inputs as basic events given to the } \\
\text { FTA. }\end{array}$ & B. 1 \\
\hline Yazdi et al. [103] & $\begin{array}{l}\text { Chemical } \\
\text { process }\end{array}$ & $\begin{array}{l}\text { Granule storage } \\
\text { process (liquid } \\
\text { storage tank } \\
\text { failure) }\end{array}$ & $\begin{array}{l}\text { Proposed a framework to compute } \\
\text { probability of TE using fuzzy set } \\
\text { theory with consideration of } \\
\text { dependency between each BE }\end{array}$ & B. 1 \\
\hline
\end{tabular}




\begin{tabular}{|c|c|c|c|c|}
\hline & & & according $\beta$ factor method. & \\
\hline Yazdi [104] & $\begin{array}{l}\text { Chemical } \\
\text { process }\end{array}$ & $\begin{array}{l}\text { Granule storage } \\
\text { process (liquid } \\
\text { storage tank } \\
\text { failure) }\end{array}$ & $\begin{array}{l}\text { Proposed a framework to compute } \\
\text { probability of TE using fuzzy set } \\
\text { theory and fuzzy AHP to obtain } \\
\text { more realistic result. }\end{array}$ & B.1 \\
\hline $\begin{array}{l}\text { Yazdi and Kabir } \\
{[105]}\end{array}$ & $\begin{array}{l}\text { Chemical } \\
\text { process }\end{array}$ & $\begin{array}{l}\text { Ethylene } \\
\text { transportation line } \\
\text { unit (Ignition of } \\
\text { vapour cloud). }\end{array}$ & $\begin{array}{l}\text { Proposed an approach due to risk } \\
\text { analysis in chemical process } \\
\text { industries considering uncertainty } \\
\text { conditions and dependency of basic } \\
\text { event utilizing fuzzy logic and } \\
\text { Bayesian network, respectively. }\end{array}$ & B.1, C \\
\hline $\begin{array}{l}\text { Jiang and Wang } \\
\text { [106] }\end{array}$ & Railways & $\begin{array}{l}\text { Chinese train } \\
\text { control system } \\
\text { (system failure) }\end{array}$ & $\begin{array}{l}\text { Introduced a framework according } \\
\text { to fuzzy logic in order to cope with } \\
\text { imprecise expert judgement in FTA. }\end{array}$ & B. 1 \\
\hline $\begin{array}{l}\text { Yazdi and Zarei } \\
\text { [107] }\end{array}$ & $\begin{array}{l}\text { Chemical } \\
\text { process }\end{array}$ & $\begin{array}{l}\text { Dramatic accident } \\
\text { BP on March } 2005 \\
\text { (Hydrocarbon } \\
\text { release) }\end{array}$ & $\begin{array}{l}\text { Proposed a framework to estimate } \\
\text { the basic event probability in FTA } \\
\text { using several applications of fuzzy } \\
\text { logic. } \\
\text { The results of different methods are } \\
\text { compared and the advantages and } \\
\text { disadvantages are discussed. }\end{array}$ & B. 1 \\
\hline Yazdi et al. [108] & $\begin{array}{l}\text { Chemical } \\
\text { process }\end{array}$ & $\begin{array}{l}\text { Spherical } \\
\text { hydrocarbon } \\
\text { storage tank (fire } \\
\text { and explosion) }\end{array}$ & $\begin{array}{l}\text { Proposed a framework to compute } \\
\text { the probability of TE using FFTA } \\
\text { and fuzzy modified TOPSIS to } \\
\text { obtained effectiveness reduction of } \\
\text { TE probability. }\end{array}$ & B. 1 \\
\hline $\begin{array}{l}\text { Yazdi and Soltanali } \\
\text { [109] }\end{array}$ & Automotive & $\begin{array}{l}\text { Fluid filling } \\
\text { system }\end{array}$ & $\begin{array}{l}\text { Proposed a framework using } \\
\text { intuitionistic fuzzy set to compute } \\
\text { the probability of TE. }\end{array}$ & B.1, C \\
\hline Yazdi [110] & Automotive & $\begin{array}{l}\text { Fluid filling } \\
\text { system }\end{array}$ & $\begin{array}{l}\text { Proposed a framework using } \\
\text { intuitionistic fuzzy set theory to } \\
\text { estimate basic events and top event } \\
\text { probability. }\end{array}$ & B.1, C \\
\hline $\begin{array}{l}\text { Yazdi and Kabir } \\
\text { [111] }\end{array}$ & $\begin{array}{l}\text { Chemical } \\
\text { process }\end{array}$ & $\begin{array}{l}\text { Release prevention } \\
\text { barrier (RPB) }\end{array}$ & $\begin{array}{l}\text { Proposed an approach for risk } \\
\text { analysis in chemical process } \\
\text { industries considering uncertain } \\
\text { conditions and dependency of basic }\end{array}$ & B.1, C \\
\hline
\end{tabular}




\begin{tabular}{|l|l|l|l|l|}
\hline & & & $\begin{array}{l}\text { event utilizing fuzzy logic, evidence } \\
\text { theory, and Bayesian network. }\end{array}$ & \\
\hline Yazdi et al. [112] & $\begin{array}{l}\text { Chemical } \\
\text { process }\end{array}$ & $\begin{array}{l}\text { Spherical } \\
\text { hydrocarbon } \\
\text { storage tank (fire } \\
\text { and explosion) }\end{array}$ & $\begin{array}{l}\text { Proposed a framework to compute } \\
\text { the probability of TE using fuzzy } \\
\text { FTA with consideration of } \\
\text { confidence level. }\end{array}$ & B.1, \\
\hline Yazdi et al. [113] & $\begin{array}{l}\text { Chemical } \\
\text { process }\end{array}$ & $\begin{array}{l}\text { A common } \\
\text { offshore platform } \\
\text { facility. }\end{array}$ & $\begin{array}{l}\text { Proposed a framework to compute } \\
\text { the probability of TE using } \\
\text { intuitionistic fuzzy FTA. }\end{array}$ & B.1 \\
\hline
\end{tabular}

Following the classification introduced earlier, some of the studies are described in more detail as follows.

One of the prior studies which used fuzzy set theory to cope with subjective uncertainty during the expert elicitation process (Strategy B.1) was performed by Celik et al. [85]. In this study, they established a risk-based modelling methodology to increase the performance of shipping accident analysis (SAI). They proposed an extension to fuzzy FTA that integrated the effects of organizational failures and shipboard technical system faults using a unique risk analysis structure. For this purpose, the similarity aggregation method (SAM) was engaged to aggregate the opinions of three employed experts. Additionally, they highlighted that the use of linguistic terms is a proper alternative to deal with the uncertainties that arise from basic event probability

Yazdi and Zarei [107] used different common extensions of fuzzy set theory to aggregate experts' opinions, which are expressed as linquitic terms about the possibility of each BE. They compared the results and listed several advantages and disadvantages of each approach. Yazdi et al. [108] also used fuzzy set theory in the same way as the previous study to obtain the probability of a chemical accident for a hydrocarbon storage tank. They developed the methodology by providing several corrective actions to reduce the probability of each basic event and subsequently the top event probability. Fuzzy TOPSIS (technique for order of preference by similarity to ideal solution) and fuzzy AHP were engaged for this purpose. The effectiveness of their proposed approach was illustrated by applying it in an industrial application.

Markowski et al. [84] used strategy B.2 (fuzzy confidence selection) to deal with uncertainty and imprecision due to problem solving where uncertainty related to knowledge have a high possibility to occur during obtaining the probability of basic events. They concluded that the proposed methodology for computing the basic event's probability confirmed that the outputs are more reliably obtained and have high merits over the conventional single point estimation. They also discussed how the chief accomplishment of the approach is due to the failure data quality during elicitation as well as on the collaboration with industrial sector plants. Finally, Martorell et al. [93] evaluated the risk impacts of variations to limited time using the license source in the nuclear power plant by addressing model and epistemic uncertainty. Like fuzzy set theory (Strategy B.2), they used different confidence levels. As the selection cannot be fuzzy set theory rules, we consider this paper as independent to other categories. 
However, the results conclude that the proposed approach has the capability to identify, treat, and analyse epistemic uncertainty based on input variables.

We found no study utilising strategy A (using lognormal distribution) for computing the probability of BEs in the journals reviewed. Bedford and Cooke [114] discussed how FTA is based on the decision making process either using reliability data handbook or expert elicitation to obtain failure rate of BEs. In other words, it means that the subjectivity issue is an unavoidable factor in each step of FTA. Therefore, they introduced a lognormal distribution with different confidence levels for this purpose. For a specific case study, using a lognormal distribution with consideration of the standard deviation and mean value can provide significant reduction in subjective uncertainty for further calculations in FTA [114].

Furthermore, subjectivity review analysis showed that the fuzzy logic based methods (strategy B) and elicitation process using fuzzy set theory (strategy B.1) have been highly engaged in different types of industrial sectors whereas the strategies B.2 and B.3 were used for more specific purposes. It can be notified that fuzzy modelling or fuzzy IF-THEN rules (strategy B.3) are more time consuming and have high computational complexity, which force system analysers and decision makers to use applications like MATLAB. Thus, using such software is not applicable in industrial sector, whereas it may be more suitable for academia. Strategy B.2 (fuzzy confidence selection) can introduce ambiguity for decision makers making their final decisions about TE probability. Strategy B.2 can be useful when assessors are willing to analyse system behaviour at different confidence levels of reliability. When reliability data is available in the industrial sector, assessors seem to prefer to use the exact value instead of using a set of values, which introduces many complexities accordingly.

Bayesian networks (Strategy C), because of their updating feature, can reduce uncertainty by putting new information into the system. As mentioned in the literature, subjective uncertainty can be reduced over time because of the increased knowledge that we can gain during system operation, which in turn provides more certainty for making decisions. Thus, BNs can be a successful way to reduce uncertainty in FTA. However, combining these strategies, such as strategy B.1 and C, as was done in some recent studies, can provide more reliable results. It seems that the future trend will be to use a combination of different strategies to cope with subjectivity. However, introducing a new method can always provide chances for further epistemic uncertainty handling.

\section{Methodological and empirical contributions to aleatory uncertainty handling}

FTA for complex engineering systems inevitably involves ambiguities arising from uncertainties in models and limitations of the models. The recognition of ambiguities is necessary for effective uncertainty handling. Many strategies have been utilized to cope with aleatory uncertainty in recent years and the three most common are described below.

- D: Probability distribution (p-percentile value) 
- E: Evidence theory

- F: Bayesian network

\subsection{Objective uncertainty handling using probability theory}

The use of probability distributions is the most common approach to dealing with uncertainty with respect to a quantity, whether epistemic or aleatory. The output probability distribution is a demonstration of the decision makers' belief degree which means that it is the probability of the measured quantity to obtain an accepted value. An explanation of the approach with respect to the unknown quantities and converting into probability distributions is provided below (Strategy D). Once a body of evidence (such as operating experience) becomes available, it is usual to modify the probability distribution in order to reproduce the updated information. Bayes' theorem is extensively applied as an analytical tool to update probability distributions.

The variability of failure and repair times of the components causes that the increasing number of probabilistic model to compute the failure probability. Two reliability curves are illustrated in Figure 7 as well as corresponding failure rates. The probable reliability value at time $t$ is shown for both curves. Figure 8 illustrates three different curves for cases where $\lambda$ is equal to the fifth, fifteenth, and ninety-fifth percentiles of $\pi(\lambda)$. In these figures, the vague quantity $T$ is supposed to be normally distributed having standard deviation 0.8 and mean 10 .

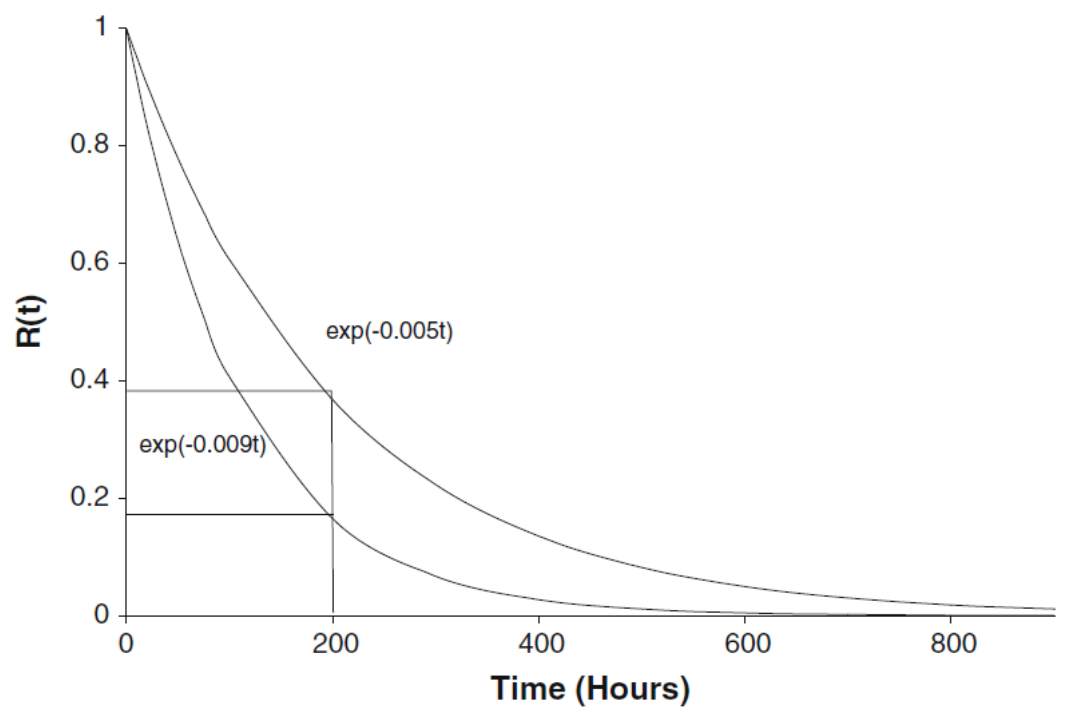

Figure 7. The reliability curves with consideration of epistemic uncertainty 


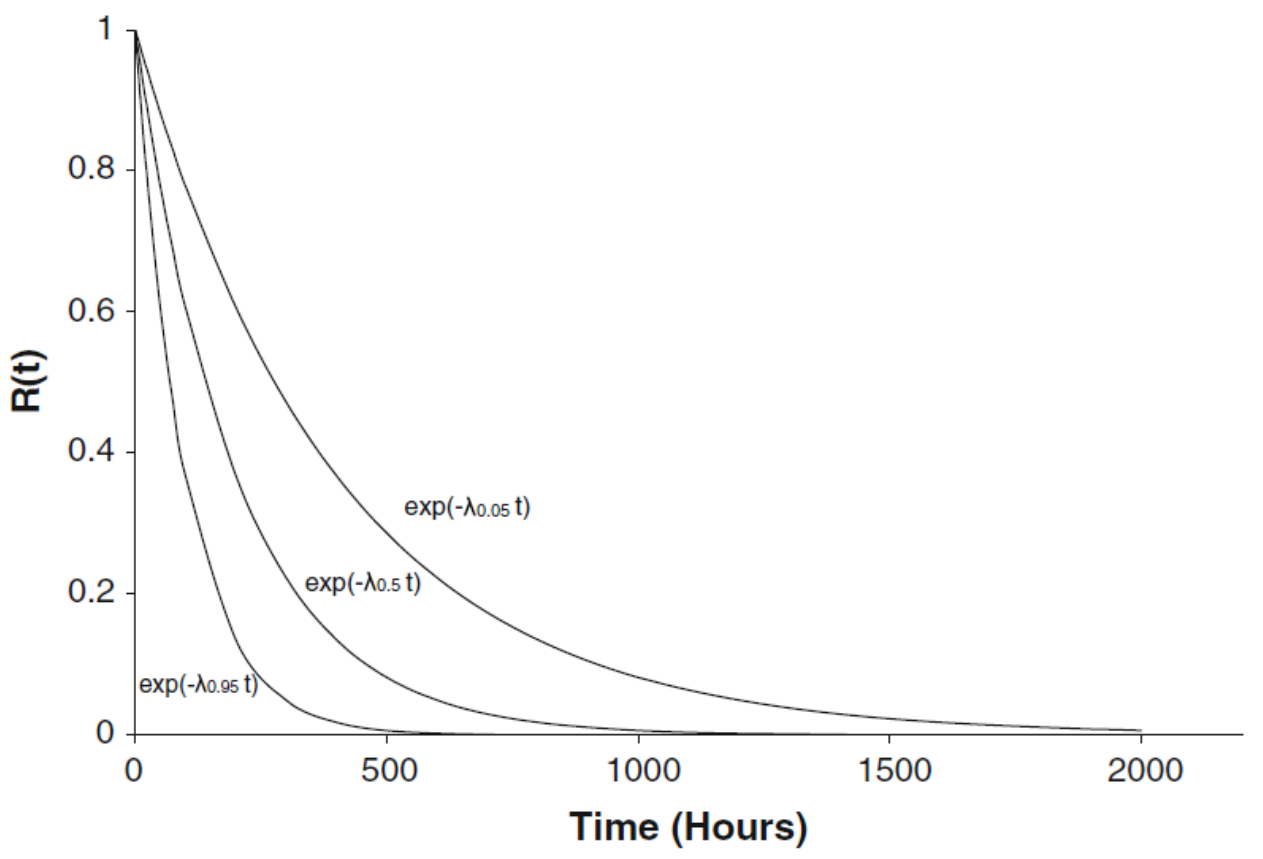

Figure 8 . The three different aleatory curves with consideration of continuous epistemic distribution

Epistemic uncertainty is also handled in this method. A p-percentile value of a random variable is a common method for this purpose. Take the sample $\left(x_{1}, x_{2}, \ldots, x_{n}\right)$. It can be expressed as a parameter value e.g. $p \%$ of the data is equal or less than to $x_{p}$. For more details one can refer to [115].

\subsection{Objective uncertainty handling using evidence theory}

Evidence theory was first proposed by Dempster and further established by Shafer (Strategy E). This theory is also known as the D-S theory and is used to overcome the uncertainty of imprecision embedded in the evidence [116,117]. Generally, the evidence theory is denoted by some important preliminary notations including a base of discernment, BPA (basic probability of assignment), and D-S combination rule, which are briefly explained as follows.

Consider $\Omega=\left\{H_{1}, H_{2}, H_{3}, \ldots, H_{N}\right\}$ is a frame of discernment and is a limited non-empty set including $N$ elements, which are mutually exhaustive and exclusive. $P(\Omega)$ is denoted as a power set formulated of $2^{N}$ elements $(\Omega)$. In addition, the basic probability of assignments (BPAs) is defined as a conversion of $P(\Omega)$ in interval 0 and 1 which means that $m: P(\Omega) \rightarrow[0,1]$, and satisfies the following conditions.

$m(\varnothing)=0, \sum_{A \in P(\Omega)} m(A)=1$

where $m(A)$ is the mass and signifies how strongly the evidence supports $A . m(\Omega)$ characterizes the evidence uncertainty. 
In circumstances of information shortage, the logical solution is to extend two bounds to the final outputs of the uncertainty description. The entire belief degree in " $A$ " is stated by an interval bound as $[\operatorname{Bel}(A), P l(A)]$ that fall between zero and one as illustrated in Figure 9. $\operatorname{Bel}()$ and $P l()$ are denoted as:

$\operatorname{Bel}(A)=\sum_{c \in A} m(C):$ Belief

$\operatorname{Pl}(A)=\sum_{c \cap A \neq \Phi} m(C):$ Plausibility

The summation of the BPAs will represent the $\operatorname{Bel}(A)$. In addition, the plausibility degree $\operatorname{Pl}(A)$ is computed by enhancing the BBAs with intersection by $A$ where it is not an empty set.

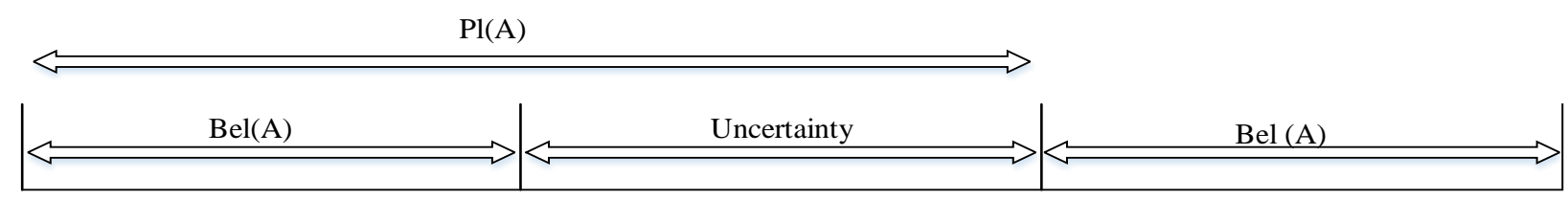

Figure 9. Plausibility $(\mathrm{Pl})$ and Belief $(\mathrm{Bel})$

The D-S combination rule integrates two BPAs in a way such that the new BPA denotes an agreement of causal parts of evidence. The D-S combination rule is the orthogonal summation of $m_{1}$ and $m_{2}$ which is defined as [118]:

$\mathrm{m}(\mathrm{A})=\left[\mathrm{m}_{1} \oplus \mathrm{m}_{2}\right](\mathrm{A})=\left\{\begin{array}{lll}0 & \text { if } & \mathrm{m}_{1} \cap \mathrm{m}_{2}=\emptyset \\ \frac{\sum_{\mathrm{A}_{I} \cap \mathrm{A}_{I I}=\mathrm{A}_{\mathrm{i}}} \mathrm{m}_{1}\left(\mathrm{~A}_{\mathrm{I}}\right) \mathrm{m}_{2}\left(\mathrm{~A}_{\mathrm{II}}\right)}{1-\sum_{\mathrm{A}_{\mathrm{I}} \cap \mathrm{A}_{\mathrm{II}}=\emptyset} \mathrm{m}_{1}\left(\mathrm{~A}_{\mathrm{I}}\right) \mathrm{m}_{2}\left(\mathrm{~A}_{\mathrm{II}}\right)} & \text { if } & \mathrm{m}_{1} \cap \mathrm{m}_{2} \neq \varnothing\end{array}\right\}$

where $A, A_{I}$, and $A_{I I}$ are subsets of $2^{\mathrm{N}}$.

"Bet" estimation can be defined to give a pignistic probability function which in the belief arrangement will satisfy $\operatorname{Bet}(\mathrm{P}): \Omega \rightarrow[0,1]$ with the same concept as the defuzzification procedure frequently used to signify the defuzzified value of the last event $[119,120]$. It can be estimated as:

$\operatorname{Bet}(A)=\sum_{P \subseteq p} \frac{m\left(A_{i}\right)}{\left|A_{i}\right|} \quad$ if $m(\phi) \neq 1$

where $\left|A_{i}\right|$ is the number of elements in subset $A_{i}$.

\subsection{Objective uncertainty handling using Bayesian network}

The use of Bayesian networks to handle uncertainty in FTA was introduced in section 4.3 (subjective uncertainty). However, component failures are typically uncommon events; experimental information for variable approximation is usually sparse. Previous method may lead to extreme confidence intervals. In order to handle objective uncertainty using Eqs 6-8, the Bayesian network approach can be applied in four steps as follows (Strategy F):

Step 1: Recognition of all variables to be computed

The failure rate $(\lambda)$ and demand failure probability $\left(\lambda_{d}\right)$ should be computed.

Step 2: Obtaining prior distribution from available data 
Lognormal distribution is typically used for the prior distribution by computing the median and the error coefficient of obtained information. An error coefficient is typically used to identify the lower and the upper boundary limits in the distribution: $\lambda_{\text {lower }}=$ Median $/($ Error factor $)$ and $\lambda_{\text {upper }}=$ Median $\times$ Error factor .

The entire range is separated into $n$ intervals $\delta=\left(\lambda_{\text {upper }}-\lambda_{\text {lower }}\right) / n$ and $\lambda_{i}$ values are obtained: $\lambda_{i}=\lambda_{\text {lower }}+$ $\delta \times(i+0.5)$ where $i$ changes between 0 and $n$.

The probability density function for lognormal distribution is stated as:

$f_{d}\left(\lambda_{i}\right)=\frac{1}{\sigma \lambda_{i} \sqrt{2 \pi}} \exp \left(-\frac{1}{2}\left[\frac{\ln \lambda_{i}-\mu}{\sigma}\right]^{2}\right)$

where $\mu$ and $\sigma$ are the lognormal distribution parameters and can be calculated as $\frac{\ln (\text { Error factor) }}{1.646}$ and $\ln$ (median), respectively.

Step 3: Collection of evidence and structure of appropriate probability function

The probability function applied is the Poisson distribution. The required data (r), comprises the failures rates $(\lambda)$, the total operating time ( $T$ ), demand (D), and the demand rates (d):

$P_{i}(r$ in $T \mid \lambda)=\frac{\left(\lambda_{i} T\right)^{r}}{r !} \exp \left(-\lambda_{i} T\right)$

$P_{i}(r$ in $D \mid \lambda)=\frac{\left(\lambda_{d i} D\right)^{r}}{r !} \exp \left(-\lambda_{d} T\right)$

Step 4: Posterior distribution exploitation utilizing Bayes' Theorem

The posterior distribution using Bayes' theorem can be obtained as follows:

$p\left(\lambda_{i} \mid B\right)=\frac{p\left(\lambda_{i}\right) p\left(B \mid \lambda_{i}\right)}{\int_{\lambda} p\left(\lambda_{i}\right) p\left(B \mid \lambda_{i}\right)}$

where $p\left(\lambda_{i}\right)$ is the PDF of the continuous variable, prior probability $B$ (prior) $=f_{d}\left(\lambda_{i}\right), p\left(B \mid \lambda_{i}\right)$ is the probability of $B$, given the failure rate $\lambda_{i}$ or demand failure probability, and $p\left(\lambda_{i} \mid B\right)$ is the PDF of failure rate $\lambda_{i}$, provided the data $B$ (posterior). Thus, the posterior probability distribution may be computed based on $n$ obtained points.

\subsection{Analysis of aleatory uncertainty handling contributions}

As mentioned earlier, problems may arise when an aleatory uncertainty issue is treated as an epistemic one or in other words when both uncertainties are mixed with each other. Keeping the uncertainties separate can prevent this [63]. However, separating uncertainties from each other is a time consuming task. In order to analyse the aleatory uncertainty contributions in this section, it should be added that many studies have been done to handle both types of uncertainty simultaneously in FTA. According to Rausand and Hoyland [22], subjectivity will show itself as an unavoidable issue for computation of objective uncertainty handling. As an example, using probability distribution functions to deal with aleatory uncertainty in FTA, the input data can be the integration of expert knowledge and objective data. In this regard, section 6 covers the studies which have been done to deal with both type of uncertainties at the same time. 
Some important studies, which use strategies D, E, and F as input to the FTA, are analysed below.

Hsiao and $\mathrm{Lu}$ [121] highlighted the effects of uncertain parameters on the model reliability for a system protection scheme. They proposed an approach for the analysis of a risk-informed SPS design refinement that incorporates input uncertainty and sensitivity analysis in FTA. In their proposed method, probability distribution (strategy D) is used to obtain failure data to use as an input in FTA. In this case, use of uncertainty bounds is suggested to handle both types of uncertainties as a direction for further studies.

Yang et al. [122] utilized the fuzzy evidence theory (strategy E) in maritime security risk assessment. They state that there is a strong requirement for having an approach that takes into account several collection criteria, including the effectiveness of measuring cost according to the reasonable security analysis. The reason is that conventional methods cannot properly deal with the circumstances having high level of uncertainty. These methods also have lack of capability of processing diverse data in a utility form suitable as input to a risk inference mechanism. Thus, to cope with these problems, which may commonly occur during FTA procedure, they used strategy E. In the same way, Simon and Weber [123] used strategy E to perform a failure analysis in the chemical process industry. In this approach, component failure probabilities are modelled as real, interval, and fuzzy numbers to calculate the imprecise reliability of a complex system. A similar study was performed by Kelly and Smith [124].

Yang et al. [125] used probability distribution to analyze aleatory uncertainty in FTA (Strategy D). They tried to understand all levels of uncertainty during the risk assessment related to the major hazards in the chemical industry. However, they used a Bayesian network to update failure rates of the components in order to combine the generic failure data from database and real life data about equipment failure from plant operation to gain knowledge about system reliability. The result showed that the uncertainty in the probabilities of basic events have a considerable impact on the top event probability. Thus, the approach integrates strategies $\mathrm{D}$ and $\mathrm{F}$, which helps to reduce uncertainty using the Bayesian updating mechanism on the probability of basic events distribution.

Wang et al. [126] proposed an approach which integrates Markov models and Bayesian networks to analyze a dynamic Bayesian network. They showed that their proposed approach is useful for estimating the dynamic probability of fire on an offshore platform. The method initially adapted HFACS (human factor analysis and classification system) based on FTA and accordingly converted the FTA to a Bayesian network for further analysis. Evidence theory (strategy E) is utilized to compute the prior probability of each failure based on historical data which enables handling of objective uncertainty. Another study by El-Gheriani et al. [127] used strategy $\mathrm{F}$ to address the objective uncertainty between aggregated data.

In addition, it seems that as with subjective uncertainty handling, the integration of strategies like probability theory and the Bayesian updating mechanism can handle aleatory uncertainty in FTA and the trend of publishing papers on this topic is likely to increase. 
Furthermore, in recent years, one of the popular ways of handling aleatory uncertainty is the use of the Bayesian updating mechanism, similar to Strategy $\mathrm{C}$ in subjective uncertainty handling. The main difference with strategy $\mathrm{F}$ is that in this case, FT is firstly mapped into the corresponding Bayesian network and then objective data are used to estimate the top event probability. However, a Bayesian network can update the probability of each input by providing new information, whether it be objective or subjective. After [128], which compared the use of Bayesian networks and FTA to estimate the top event probability, many studies have been performed to estimate the probability of TE by mapping FTs into the corresponding BNs, e.g. [79,128-138]. As can be seen from Figure 10, the popularity of papers on this topic has increased in recent years.

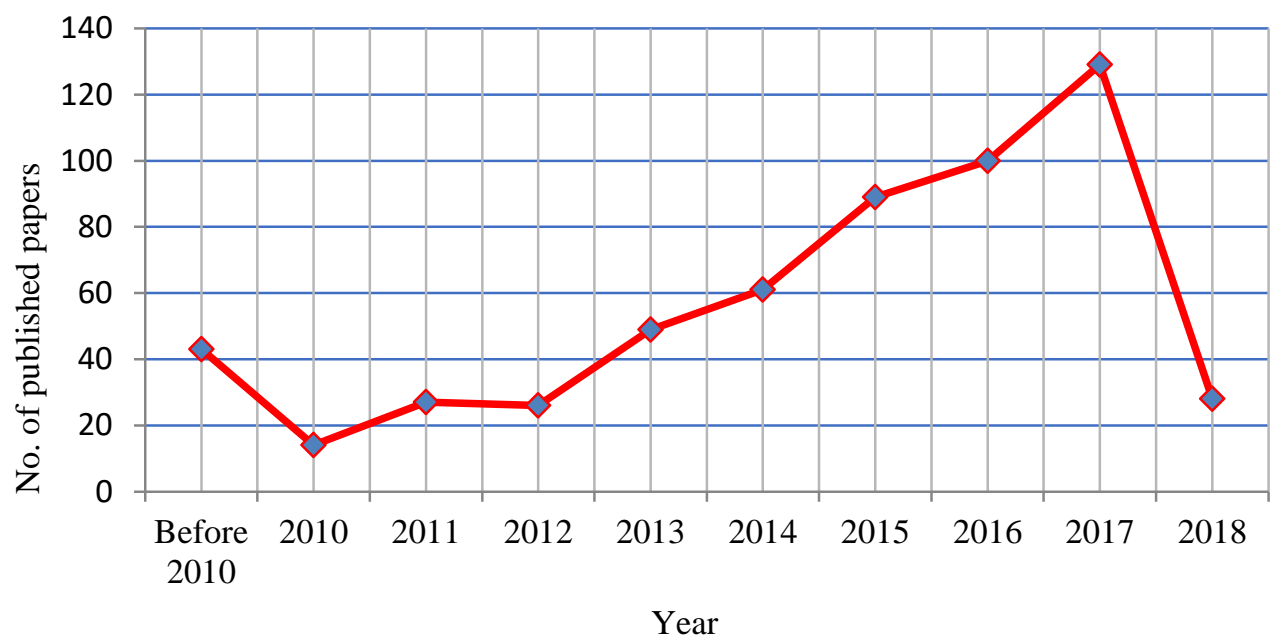

Figure 10. Distribution of publications on Bayesian network used in the context of safety

\section{Methodological and empirical contributions integrating both epistemic and aleatory uncertainty handling}

Classically, researchers have often stated that distinguishing between epistemic and aleatory uncertainty is unnecessary. The reason is that based on the axioms of expected-utility decision assessment $[139,140]$, it is unrelated in rational selections [141]. Yet, all it requires is a general technique to handle both types of uncertainty. The Bayesian probability strategy is one such technique which has enough scope to describe both epistemic and aleatory uncertainty. The diverse probability approaches can then be utilized for the decision making procedure. In this regard, according to classical points of view, a return to the conventional distinction between epistemic and aleatory uncertainty may appear as a step backwards. However, the authors believed that rationality may be viewed as much more complicated. Therefore, it is necessary for decision makers to be fully aware of the importance and the uncertainty sources before making a knowledgeable decision.

Table 2 summarizes the approaches that integrate both epistemic and aleatory uncertainty handling in a single framework. 
Table 2. Approaches to handle both epistemic and aleatory uncertainty through FTA in various industrial sectors

\begin{tabular}{|c|c|c|c|c|}
\hline Reference & $\begin{array}{l}\text { Industrial } \\
\text { sectors }\end{array}$ & $\begin{array}{l}\text { Application fields } \\
\text { (failure) }\end{array}$ & Highlights & Strategy \\
\hline Ferdous et al. [142] & $\begin{array}{l}\text { Chemical } \\
\text { process }\end{array}$ & $\begin{array}{l}\text { Liquefied petroleum } \\
\text { gas (LPG) (runaway } \\
\text { reaction) }\end{array}$ & $\begin{array}{l}\text { Proposed an approach which } \\
\text { emphasises uncertainty handling in } \\
\text { qualitative risk assessment (QRA). } \\
\text { The approach used evidence theory } \\
\text { and fuzzy set theory to handle the } \\
\text { uncertainties probability of basic } \\
\text { events. }\end{array}$ & $\mathrm{B}$ and $\mathrm{E}$ \\
\hline Ferdous et al. [143] & Marine & $\begin{array}{l}\text { Offshore platform } \\
\text { (leak from facility) }\end{array}$ & $\begin{array}{l}\text { Proposed an approach to deal with } \\
\text { both types of uncertainty and } \\
\text { minimizing the uncertainty, } \\
\text { combining expert knowledge and } \\
\text { prior knowledge updating. }\end{array}$ & $\mathrm{B}, \mathrm{E}$, and $\mathrm{F}$ \\
\hline Ferdous et al. [144] & $\begin{array}{l}\text { Chemical } \\
\text { process }\end{array}$ & $\begin{array}{l}\text { Fire and explosion in } \\
\text { Blow down drum } \\
\text { (Hydrocarbon } \\
\text { release) }\end{array}$ & $\begin{array}{l}\text { Attempted to provide expert } \\
\text { knowledge to deal with unknown } \\
\text { information and used evidence } \\
\text { theory and fuzzy set theory to } \\
\text { analyze both types of uncertainties. }\end{array}$ & $\mathrm{B}$ and $\mathrm{E}$ \\
\hline Martorell et al. [145] & Nuclear & $\begin{array}{l}\text { Reactor protection } \\
\text { system (failure to } \\
\text { insert two or more } \\
\text { rods) }\end{array}$ & $\begin{array}{l}\text { Proposed an approach for } \\
\text { recognition, treatment, and } \\
\text { assessment of both types of } \\
\text { uncertainties by integrating them. }\end{array}$ & $\mathrm{A}$ and $\mathrm{D}$ \\
\hline Khalil [146] & $\begin{array}{l}\text { Chemical } \\
\text { process }\end{array}$ & $\begin{array}{l}\text { The systems of } \\
\text { hoydrogen storage for } \\
\text { light-duty vehicles } \\
\text { (dust cloud } \\
\text { explosion) }\end{array}$ & $\begin{array}{l}\text { Introduced an approach to deal both } \\
\text { types of uncertainty by developing } \\
\text { a QRA. }\end{array}$ & $\mathrm{A}$ and $\mathrm{D}$ \\
\hline Shoar et al. [147] & $\begin{array}{l}\text { Chemical } \\
\text { process }\end{array}$ & $\begin{array}{l}\text { Arc welding process } \\
\text { (Incomplete } \\
\text { penetration }\end{array}$ & $\begin{array}{l}\text { Proposed hybrid uncertainty } \\
\text { analysis methods and camping with } \\
\text { transformation method. }\end{array}$ & $\mathrm{A}$ and $\mathrm{E}$ \\
\hline $\begin{array}{l}\text { El-Gheriani et al. } \\
{[148]}\end{array}$ & Marine & $\begin{array}{l}\text { Oil and gas well (gas } \\
\text { leakage) }\end{array}$ & $\begin{array}{l}\text { Used probability theory and } \\
\text { Bayesian formalism to cope with } \\
\text { source to source uncertainty within } \\
\text { the combined information for each } \\
\text { basic events and a exact value for }\end{array}$ & $\mathrm{A}$ and $\mathrm{F}$ \\
\hline
\end{tabular}




\begin{tabular}{|c|c|c|c|c|}
\hline & & & interest value. & \\
\hline Li et al. [149] & Marine & $\begin{array}{l}\text { Pipelines of subsea } \\
\text { (third party damage } \\
\text { caused) }\end{array}$ & $\begin{array}{l}\text { Introduced a dynamic framework } \\
\text { for risk assessment with } \\
\text { consideration of uncertainty } \\
\text { circumstances demonstrated by } \\
\text { third-party damage. }\end{array}$ & $\begin{array}{l}\mathrm{B}, \mathrm{C} \text {, and } \\
\mathrm{E}\end{array}$ \\
\hline
\end{tabular}

As can be seen, wide varieties of methods have been combined in recent years to deal with both types of uncertainties in the same study. Probability theory and Bayesian networks are more commonly used in this regard. However, application of Bayes' theorem provides many advantages over the conventional probability theorem based approaches. It seems that the combined application of fuzzy set and evidence theory will grow in the future. However, it should be noted that in order to achieve reliable results based on separation of uncertainty types, such combination strategies will be costly. For example, expert knowledge must account for the separation, and there is massive effort involved in keeping the uncertainty consistently distinct. Furthermore the information must be presented in two dimensions and applying sensitivity analysis must also take this into account.

The separation of uncertainties allows us to review and summarize the variability of the studied population, i.e. how decision makers can exactly reference each component and how they can measure the uncertainties based on the lack of knowledge [150].

\section{Discussion and Conclusion}

Over the years, several methods have been established for risk analysis in different industries. FTA is one of the most widely used approaches for risk assessment. Like other approaches, uncertainty is unavoidable in fault treebased risk assessment techniques. Although in some contexts the terms risk and uncertainty are used interchangeably, in this paper, these two terms are assumed to be different. From this point of view, different uncertainty handling approaches for fault tree based risk assessment methodologies are reviewed.

In order to accomplish a proper FTA, probability inputs such as basic event failure probabilities are required. It is commonly difficult to obtain a precise probability for the occurrence of a basic event. Two types of uncertainties, such as epistemic and aleatory are encountered during obtainment of basic event probabilities. Many strategies have been considered in the literature, including probability theory, fuzzy set theory, Bayesian theorem, evidence theory, and so on to cope with both types of uncertainties. The viewpoints of each strategy are analyzed in this paper. The theoretical and fundamental contributions to uncertainty handling in risk assessment are reviewed to understand how it can be further developed.

Reviewing the existing strategies, we found that a number of methods have been developed to deal with the uncertainty in PRA methods. However, the vast majority of these strategies cannot be applied in all circumstances. Besides, it may be difficult to explain the reason for choosing a particular strategy to deal with a particular type of 
uncertainty and whether the chosen strategies are valuable to be researched. Moreover, the application of the most existing strategies is confined to a narrow set of fields or activities. PRA methods cover various areas, therefore it is necessary to promote the overall benefit of a strategy to deal with uncertainty from a general viewpoint.

Table 3 shows a comparison between different strategies with regards to their ability to handle uncertainty while satisfying different criteria. As it can be seen from Table 3, with compared to the standalone strategies, integration strategies have much ability to deal with the uncertainty and cover most of the specified criteria. In other words, the integration strategies can promote the overall welfare of a strategy in handling uncertainty in PRA methods.

Table 3. Comparison of strategies based on different criteria

\begin{tabular}{|c|c|c|c|c|c|c|c|c|c|c|c|c|}
\hline \multirow[b]{2}{*}{ Criteria } & \multicolumn{3}{|c|}{$\begin{array}{l}\text { Epistemic } \\
\text { strategies }\end{array}$} & \multicolumn{3}{|c|}{$\begin{array}{l}\text { Aleatory } \\
\text { strategies }\end{array}$} & \multicolumn{6}{|c|}{ Integration strategies } \\
\hline & $\mathbf{A}$ & B & $\mathbf{C}$ & D & $\mathbf{E}$ & $\mathbf{F}$ & $B$ and $E$ & $\mathrm{~B}, \mathrm{E}$, and $\mathrm{F}$ & $A$ and $D$ & $A$ and $E$ & $A$ and $F$ & $\mathrm{~B}, \mathrm{C}$, and $\mathrm{E}$ \\
\hline C.1 & $x$ & $\checkmark$ & $\checkmark$ & $x$ & $x$ & $x$ & $\checkmark$ & $\checkmark$ & $x$ & $x$ & $x$ & $\checkmark$ \\
\hline C. 2 & $\checkmark$ & $\checkmark$ & $x$ & $\checkmark$ & $\checkmark$ & $x$ & $\checkmark$ & $\checkmark$ & $x$ & $\checkmark$ & $x$ & $\checkmark$ \\
\hline C.3 & $x$ & $x$ & $\checkmark$ & $x$ & $x$ & $\checkmark$ & $x$ & $\checkmark$ & $x$ & $x$ & $\checkmark$ & $\checkmark$ \\
\hline C.4 & $\checkmark$ & $\checkmark$ & $\checkmark$ & $x$ & $x$ & $\checkmark$ & $\checkmark$ & $\checkmark$ & $\checkmark$ & $\checkmark$ & $\checkmark$ & $\checkmark$ \\
\hline $\begin{array}{l}\text { Note: " } \\
\text { A: Proba } \\
\text { B: Fuzzy } \\
\text { C: Bayes } \\
\text { D: Proba } \\
\text { E: Evide } \\
\text { F: Bayes } \\
\text { C.1: Fuz } \\
\text { C.2: Loc } \\
\text { C.3. Upd } \\
\text { C.4: Ada }\end{array}$ & $\begin{array}{l}\text { mea } \\
\text { lity } \\
\text { ogic } \\
\text { n ne } \\
\text { lity } \\
\text { e th } \\
\text { n ne } \\
\text { ness } \\
\text { and } \\
\text { ing }\end{array}$ & $\begin{array}{l}\text { th } \\
\text { stri } \\
\text { ase } \\
\text { vor } \\
\text { stri } \\
\text { rry } \\
\text { vor } \\
\text { f li } \\
\text { lob } \\
\text { for }\end{array}$ & $\begin{array}{l}\text { typ } \\
\text { uist } \\
\text { elic } \\
\text { tio }\end{array}$ & $\begin{array}{l}\text { Wo } \\
\text { sca } \\
\text { atio } \\
82\end{array}$ & $\begin{array}{l}\text { abil } \\
\text { one) }\end{array}$ & $y$ to & $\begin{array}{l}\text { ddress the } \\
\text { dy [152] }\end{array}$ & sue and " $\times$ " $\mathrm{m}$ & eans the $m$ & hod canno & address th & issue. \\
\hline
\end{tabular}

Hence, compared with existing standalone strategies, the integration of strategies, including $\mathrm{B}, \mathrm{C}$, and $\mathrm{E}$ has more capability to deal with the uncertainty and they are more applicable in different circumstances which inherently has a linguistic assessment process, confirm the local and global elicitation, following the updating mechanism, and can properly adapt to different conditions.

Although extensive research has been performed, there exist many challenges that need additional research. For instance, the review illustrates that a broad diversity of fuzzy membership functions has been used and they vary across application areas. As the definition of a proper membership function has a high effect on the final outputs of the risk analysis, it is important to have a reliable methodology to show how to provide a membership function. In addition, in this study, most of the fault tree analysis methods taken into account are static; most of the reviewed papers assumed components can only either be in failed or non-failed state. However, in complex systems, 
components can operate in more than two states. Hence, there is scope to perform further research for uncertainty handling by considering multi-state systems. Moreover, additional research needs to be carried out to assess dynamic extensions of fault tree analysis under conditions of uncertainty.

The review showed that integration of strategies has a strong ability to handle both types of uncertainties. However, most of the efforts have been made to deal with epistemic uncertainty, suggesting it is regarded as being more important than aleatory uncertainty. It is necessary to note that iteration of the analysis is highly recommended when most of the mentioned strategies are used. In this regard, integrating strategies such as using a Bayesian updating mechanism could be considered as the most appropriate method for such an iteration of the analysis. In recent years, as stated in [153], Bayesian updating mechanisms have been widely used as an alternative method to fault tree analysis because of their flexible architecture and ability to reason about uncertainty. In light of the multiple merits provided by the Bayesian updating mechanism, it is worth additional exploration.

Another important issue worth mentioning is that most of the uncertainty handling approaches reviewed in this paper perform the analysis under the assumption that a priori knowledge about the system architecture is always available. However, the advancement of technologies has brought loosely connected systems. Typical examples of such systems are Cyber-Physical Systems and the Internet of Things. These are systems where temporary system architectures/configurations are formed during operation by combining several smaller systems and these architectures may cease to exist after a certain period of time to form a new architecture. As a result, there may exist infinite possible configurations of such a system, and it is difficult to ensure certainty about a particular system architecture during risk assessment. Therefore, risk assessment of such open systems would require taking into account the uncertainty of the system architecture at a certain point in time. This opens new research avenues to investigate how a meaningful risk assessment can be performed for open and adaptive systems by taking into account the architectural uncertainty.

\section{References}

[1] National Research Council. Science and Judgment in Risk Assessment, Committee on Risk Assessment of Hazardous Air Pollutants. Washington, D.C.: National Academies Press; 1994. doi:10.17226/2125.

[2] National Research Council. Science and Decisions. Washington, D.C.: National Academies Press; 2009. doi:10.17226/12209.

[3] Ferson S, Ginzburg LR. Different methods are needed to propagate ignorance and variability. Reliab Eng Syst Saf 1996;54:133-44. doi:10.1016/S0951-8320(96)00071-3.

[4] Mahmood, Y.A., Ahmadi, A., Verma, A.K., Srividya, A., Kumar, U. Fuzzy fault tree analysis : a review of concept and application, Int. J. Syst. Assur. Eng. Manag. 2013;4:19-32. doi:10.1007/s13198-013-0145-x. 
[5] Kabir, S., Papadopoulos, Y. A review of applications of fuzzy sets to safety and reliability engineering, Int. J. Approx. Reason. 2018;100:29-55. doi:10.1016/j.ijar.2018.05.005.

[6] Reniers G, Anthone Y. A ranking of safety journals using different measurement methods. Saf Sci 2012;50:1445-51. doi:10.1016/j.ssci.2012.01.017.

[7] Klinke A, Renn O. A New Approach to Risk Evaluation and Management: Risk-Based, Precaution-Based, and Discourse-Based Strategies 1. Risk Anal 2002;22:1071-94. doi:10.1111/1539-6924.00274.

[8] Aven T. Risk analysis : assessing uncertainties beyond expected values and probabilities. Wiley; 2008.

[9] IRGC. White Paper on Risk Governance. Towards An Integrative Approach. Tech. Rep.,. 2005.

[10] Camerer C, Weber M. Recent developments in modeling preferences: Uncertainty and ambiguity. J Risk Uncertain 1992;5:325-70. doi:10.1007/BF00122575.

[11] Basili M. A Rational Decision Rule with Extreme Events. Risk Anal 2006;26. doi:10.1111/j.15396924.2006.00826.x.

[12] Dubois D. Representation, Propagation, and Decision Issues in Risk Analysis Under Incomplete Probabilistic Information. Risk Anal 2010;30:361-8. doi:10.1111/j.1539-6924.2010.01359.x.

[13] Hatami-Marbini A, Tavana M, Moradi M, Kangi F. A fuzzy group Electre method for safety and health assessment in hazardous waste recycling facilities. Saf Sci 2013;51:414-26.

doi:10.1016/J.SSCI.2012.08.015.

[14] Colyvan M. Is Probability the Only Coherent Approach to Uncertainty? Risk Anal 2008;28. doi:10.1111/j.1539-6924.2008.01058.x.

[15] Aven T, Zio E. Some considerations on the treatment of uncertainties in risk assessment for practical decision making. Reliab Eng Syst Saf 2011;96:64-74. doi:10.1016/J.RESS.2010.06.001.

[16] Catrinu MD, Nordgård DE. Integrating risk analysis and multi-criteria decision support under uncertainty in electricity distribution system asset management. Reliab Eng Syst Saf 2011;96:663-70. doi:10.1016/J.RESS.2010.12.028.

[17] Richter A, Koch C. Integration, differentiation and ambiguity in safety cultures. Saf Sci 2004;42:703-22. doi:10.1016/J.SSCI.2003.12.003.

[18] Faber MH. On the Treatment of Uncertainties and Probabilities in Engineering Decision Analysis. J Offshore Mech Arct Eng 2005;127:243. doi:10.1115/1.1951776.

[19] Kiureghian A Der, Ditlevsen O. Aleatory or epistemic? Does it matter? Struct Saf 2009;31:105-12. doi:10.1016/J.STRUSAFE.2008.06.020. 
[20] Aven T. Risk management and governance. Springer-Verlag Berlin An; 2013.

[21] Jin H, Lundteigen MA, Rausand M. Uncertainty assessment of reliability estimates for safety-instrumented systems. Proc Inst Mech Eng Part O J Risk Reliab 2012;226:646-55. doi:10.1177/1748006X12462780.

[22] Rausand M, Hoyland A. System Reliability Theory: Models, Statistical Methods, and Applications 2004:664. doi:10.1109/WESCON.1996.554026.

[23] Bari RA, Park CK. Uncertainty characterization of data for probabilistic risk assessment. Reliab Eng Syst Saf 1989;26:163-72. doi:DOI: 10.1016/0951-8320(89)90072-0.

[24] Parry GW. The characterization of uncertainty in probabilistic risk assessments of complex systems. Reliab Eng Syst Saf 1996;54:119-26. doi:10.1016/S0951-8320(96)00069-5.

[25] Zio E, Apostolakis GE. Two methods for the structured assessment of model uncertainty by experts in performance assessments of radioactive waste repositories. Reliab Eng Syst Saf 1996;54:225-41. doi:10.1016/S0951-8320(96)00078-6.

[26] Paté-Cornell ME. Uncertainties in risk analysis: Six levels of treatment. Reliab Eng Syst Saf 1996;54:95111. doi:10.1016/S0951-8320(96)00067-1.

[27] Winkler RL. Uncertainty in probabilistic risk assessment. Reliab Eng Syst Saf 1996;54:127-32. doi:10.1016/S0951-8320(96)00070-1.

[28] Renn O. The role of risk perception for risk management. Reliab Eng Syst Saf 1998;59:49-62. doi:10.1016/S0951-8320(97)00119-1.

[29] Morgan MG. Uncertainty Analysis in Risk Assessment. Hum Ecol Risk Assess 1998;4:25-39. doi:10.1080/10807039.1998.11009680.

[30] Murphy BL. Dealing with Uncertainty in Risk Assessment. Hum Ecol Risk Assess An Int J 1998;4:685-99. doi:10.1080/10807039891284569.

[31] Hattis D. Three Candidate \&quot;Laws\&quot; of Uncertainty Analysis1. Risk Anal 1990;10:11-11. doi:10.1111/j.1539-6924.1990.tb01013.x.

[32] Carrington CD, Bolger PM. Uncertainty and risk assessment. Hum Ecol Risk Assess 1998;4:253-7. doi:10.1080/10807039891284325.

[33] Reckhow KH. Lessons from risk assessment. Hum Ecol Risk Assess 1999;5:245-53. doi:10.1080/10807039991289392.

[34] Reid SG. Confidence and risk. Struct Saf 2009;31:98-104. doi:10.1016/j.strusafe.2008.06.006.

[35] Flage R, Aven T. On treatment of uncertainty in system planning. Reliab Eng Syst Saf 2009;94:884-90. 
doi:10.1016/j.ress.2008.09.011.

[36] Aven T, Renn O. The role of quantitative risk assessments for characterizing risk and uncertainty and delineating appropriate risk management options, with special emphasis on terrorism risk. Risk Anal 2009;29:587-600. doi:10.1111/j.1539-6924.2008.01175.x.

[37] Jones-Lee M, Aven T. The role of social cost-benefit analysis in societal decision-making under large uncertainties with application to robbery at a cash depot. Reliab Eng Syst Saf 2009;94:1954-61.

doi:10.1016/j.ress.2009.06.011.

[38] Cooke R. Conundrums with Uncertainty Factors: Perspective. Risk Anal 2010;30:330-9. doi:10.1111/j.1539-6924.2009.01336.x.

[39] Cooke R. Experts in uncertainty : opinion and subjective probability in science. Oxford University Press; 1991.

[40] Yazdi M. A review paper to examine the validity of Bayesian network to build rational consensus in subjective probabilistic failure analysis. Int J Syst Assur Eng Manag 2019. doi:10.1007/s13198-018-007577.

[41] Aven T. On how to define, understand and describe risk. Reliab Eng Syst Saf 2010;95:623-31. doi:10.1016/j.ress.2010.01.011.

[42] Aven T. On the need for restricting the probabilistic analysis in risk assessments to variability: Perspective. Risk Anal 2010;30:354-60. doi:10.1111/j.1539-6924.2009.01314.x.

[43] Markowski AS, Mannan MS, Kotynia (Bigoszewska) A. A, Siuta D. Uncertainty aspects in process safety analysis. J Loss Prev Process Ind 2010;23:446-54. doi:10.1016/j.jlp.2010.02.005.

[44] Steen R, Aven T. A risk perspective suitable for resilience engineering. Saf Sci 2011;49:292-7. doi:10.1016/j.ssci.2010.09.003.

[45] Aven T. On Different Types of Uncertainties in the Context of the Precautionary Principle. Risk Anal 2011;31:1515-25. doi:10.1111/j.1539-6924.2011.01612.x.

[46] Aven T. Selective critique of risk assessments with recommendations for improving methodology and practise. Reliab Eng Syst Saf 2011;96:509-14. doi:10.1016/j.ress.2010.12.021.

[47] Aven T. On the new ISO guide on risk management terminology. Reliab Eng Syst Saf 2011;96:719-26. doi:10.1016/j.ress.2010.12.020.

[48] Aven T, Guikema S. Whose uncertainty assessments (probability distributions) does a risk assessment report: The analysts or the experts? Reliab Eng Syst Saf 2011;96:1257-62. doi:10.1016/j.ress.2011.05.001.

[49] Aven T. The risk concept-historical and recent development trends. Reliab Eng Syst Saf 2012;99:33-44. 
doi:10.1016/j.ress.2011.11.006.

[50] Veland H, Aven T. Risk communication in the light of different risk perspectives. Reliab Eng Syst Saf 2013;110:34-40. doi:10.1016/j.ress.2012.09.007.

[51] Aven T. A conceptual framework for linking risk and the elements of the data-information-knowledgewisdom (DIKW) hierarchy. Reliab Eng Syst Saf 2013;111:30-6. doi:10.1016/j.ress.2012.09.014.

[52] Aven T. On How to Deal with Deep Uncertainties in a Risk Assessment and Management Context. Risk Anal 2013;33:2082-91. doi:10.1111/risa.12067.

[53] Aven T. Practical implications of the new risk perspectives. Reliab Eng Syst Saf 2013;115:136-45. doi:10.1016/j.ress.2013.02.020.

[54] Bjelland H, Aven T. Treatment of uncertainty in risk assessments in the Rogfast road tunnel project. Saf Sci 2013;55:34-44. doi:10.1016/j.ssci.2012.12.012.

[55] Aven T, Zio E. Foundational Issues in Risk Assessment and Risk Management. Risk Anal 2014;34:116472. doi:10.1111/risa.12132.

[56] Bjerga T, Aven T, Zio E. An illustration of the use of an approach for treating model uncertainties in risk assessment. Reliab Eng Syst Saf 2014;125:46-53. doi:10.1016/j.ress.2014.01.014.

[57] Aven T, Krohn BS. A new perspective on how to understand, assess and manage risk and the unforeseen. Reliab Eng Syst Saf 2014;121:1-10. doi:10.1016/J.RESS.2013.07.005.

[58] Aven T. On the meaning of a black swan in a risk context. Saf Sci 2013;57:44-51. doi:10.1016/J.SSCI.2013.01.016.

[59] Haugen S, Vinnem JE. Perspectives on risk and the unforeseen. Reliab Eng Syst Saf 2015;137:1-5. doi:10.1016/j.ress.2014.12.009.

[60] Aven T, Ylönen M. Safety regulations: Implications of the new risk perspectives. Reliab Eng Syst Saf 2016;149:164-71. doi:10.1016/j.ress.2016.01.007.

[61] Shortridge J, Aven T, Guikema S. Risk assessment under deep uncertainty: A methodological comparison. Reliab Eng Syst Saf 2017;159:12-23. doi:10.1016/j.ress.2016.10.017.

[62] Jensen A, Aven T. A new definition of complexity in a risk analysis setting. Reliab Eng Syst Saf 2018;171:169-73. doi:10.1016/j.ress.2017.11.018.

[63] Vose D. Risk analysis : a quantitative guide. Wiley; 2008.

[64] Martz HF. Response to \&quot;Problems with Empirical Bayes\&quot; Risk Anal 1986;6:273-4. doi:10.1111/j.1539-6924.1986.tb00218.x. 
[66] Kabir S, Walker M, Papadopoulos Y, Rüde E, Securius P. Fuzzy temporal fault tree analysis of dynamic systems. Int J Approx Reason 2016;77:20-37. doi:10.1016/j.ijar.2016.05.006.

[67] Ferdous R, Khan F, Veitch B, Amyotte PR. Methodology for computer aided fuzzy fault tree analysis. Process Saf Environ Prot 2009;87:217-26. doi:10.1016/j.psep.2009.04.004.

[68] Gentile M, Rogers WJ, Mannan MS. Development of a Fuzzy Logic-Based Inherent Safety Index. Process Saf Environ Prot 2003;81:444-56. doi:10.1205/095758203770866610.

[69] Ross TJ. Fuzzy Logic with Engineering Applications. 2009. doi:10.1002/9781119994374.

[70] Markowski AS, Sam Mannan M. ExSys-LOPA for the chemical process industry. J Loss Prev Process Ind 2010;23:688-96. doi:10.1016/j.jlp.2010.05.011.

[71] Markowski AS, Mannan MS. Fuzzy logic for piping risk assessment (pfLOPA). J Loss Prev Process Ind 2009;22:921-7. doi:10.1016/j.jlp.2009.06.011.

[72] Onisawa T. Subjective analysis of system reliability and its analyzer. Fuzzy Sets Syst 1996;83:249-69. doi:10.1016/0165-0114(95)00381-9.

[73] Onisawa T. A representation of human reliability using fuzzy concepts. Inf Sci (Ny) 1988;45:153-73. doi:10.1016/0020-0255(88)90038-2.

[74] Yazdi M. Acquiring and Sharing Tacit Knowledge in Failure Diagnosis Analysis Using Intuitionistic and Pythagorean Assessments. J Fail Anal Prev 2019. doi:10.1007/s11668-019-00599-w.

[75] Zerrouki H, Tamrabet A. Safety and Risk Analysis of an Operational Heater Using Bayesian Network. J Fail Anal Prev 2015;15:657-61. doi:10.1007/s11668-015-9986-8.

[76] Bobbio A, Portinale L, Minichino M, Ciancamerla E. Improving the analysis of dependable systems by mapping Fault Trees into Bayesian Networks. Reliab Eng Syst Saf 2001;71:249-60. doi:10.1016/S09518320(00)00077-6.

[77] Hong Y, Pasman HJ, Sachdeva S, Markowski AS, Mannan MS. A fuzzy logic and probabilistic hybrid approach to quantify the uncertainty in layer of protection analysis. J Loss Prev Process Ind 2016;43:10-7. doi:10.1016/j.jlp.2016.04.006.

[78] Bhandari J, Abbassi R, Garaniya V, Khan F. Risk analysis of deepwater drilling operations using Bayesian network. J Loss Prev Process Ind 2015;38:11-23. doi:10.1016/J.JLP.2015.08.004.

[79] Zerrouki H, Smadi H. Bayesian Belief Network Used in the Chemical and Process Industry: A Review and Application. J Fail Anal Prev 2017;17:159-65. doi:10.1007/s11668-016-0231-x. 
[80] Javadi M, Saeedi G, Shahriar K. Developing a New Probabilistic Approach for Risk Analysis, Application in Underground Coal Mining. J Fail Anal Prev 2017;17:989-1010. doi:10.1007/s11668-017-0325-0.

[81] Nielsen TD, Jensen FV. Bayesian networks and decision graphs. Second. New York, USA: Springer Science \& Business Media.LLC.; 2009.

[82] Cai B, Liu Y, Liu Z, Chang Y, Jiang L. Bayesian Networks for Reliability Engineering. Singapore: Springer Singapore; 2020. doi:10.1007/978-981-13-6516-4.

[83] Cai B, Huang L, Xie M. Bayesian Networks in Fault Diagnosis. IEEE Trans Ind Informatics 2017;13:222740. doi:10.1109/TII.2017.2695583.

[84] Markowski AS, Mannan MS, Bigoszewska A. Fuzzy logic for process safety analysis. J Loss Prev Process Ind 2009;22:695-702. doi:10.1016/j.jlp.2008.11.011.

[85] Celik M, Lavasani SM, Wang J. A risk-based modelling approach to enhance shipping accident investigation. Saf Sci 2010;48:18-27. doi:10.1016/j.ssci.2009.04.007.

[86] Mechri W, Simon C, Ben Othman K. Uncertainty analysis of common cause failure in safety instrumented systems. Proc Inst Mech Eng Part O J Risk Reliab 2011;225:450-60. doi:10.1177/1748007810395668.

[87] Mentes A, Helvacioglu IH. An application of fuzzy fault tree analysis for spread mooring systems. Ocean Eng 2011;38:285-94. doi:10.1016/j.oceaneng.2010.11.003.

[88] Shahriar A, Sadiq R, Tesfamariam S. Risk analysis for oil \& gas pipelines: A sustainability assessment approach using fuzzy based bow-tie analysis. J Loss Prev Process Ind 2012;25:505-23. doi:10.1016/j.jlp.2011.12.007.

[89] Aqlan F, Mustafa Ali E. Integrating lean principles and fuzzy bow-tie analysis for risk assessment in chemical industry. J Loss Prev Process Ind 2014;29:39-48. doi:10.1016/j.jlp.2014.01.006.

[90] Shi L, Shuai J, Xu K. Fuzzy fault tree assessment based on improved AHP for fire and explosion accidents for steel oil storage tanks. J Hazard Mater 2014;278:529-38. doi:10.1016/j.jhazmat.2014.06.034.

[91] Chen W. A quantitative fuzzy causal model for hazard analysis of man-machine-environment system. Saf Sci 2014;62:475-81. doi:10.1016/j.ssci.2013.10.001.

[92] Omidvari M, Lavasani SMRR, Mirza S. Presenting of failure probability assessment pattern by FTA in Fuzzy logic (case study: Distillation tower unit of oil refinery process). J Chem Heal Saf 2014;21:14-22. doi:10.1016/j.jchas.2014.06.003.

[93] Martorell S, Martón I, Villamizar M, Sánchez AI, Carlos S. Evaluation of risk impact of changes to Completion Times addressing model and parameter uncertainties. Reliab Eng Syst Saf 2014;130:190-201. doi:10.1016/j.ress.2014.06.003. 
[94] Lavasani SM, Ramzali N, Sabzalipour F, Akyuz E. Utilisation of Fuzzy Fault Tree Analysis (FFTA) for quantified risk analysis of leakage in abandoned oil and natural-gas wells. Ocean Eng 2015;108:729-37. doi:10.1016/j.oceaneng.2015.09.008.

[95] Ramzali N, Lavasani MRM, Ghodousi J. Safety barriers analysis of offshore drilling system by employing Fuzzy event tree analysis. Saf Sci 2015;78:49-59. doi:10.1016/j.ssci.2015.04.004.

[96] Lavasani SM, Zendegani A, Celik M. An extension to Fuzzy Fault Tree Analysis (FFTA) application in petrochemical process industry. Process Saf Environ Prot 2015;93:75-88. doi:10.1016/j.psep.2014.05.001.

[97] Duan Y, Zhao J, Chen J, Bai G. A risk matrix analysis method based on potential risk influence : A case study on cryogenic liquid hydrogen filling system. Process Saf Environ Prot 2016;102:277-87. doi:10.1016/j.psep.2016.03.022.

[98] Ahn J, Chang D. Fuzzy-based HAZOP study for process industry. J Hazard Mater 2016;317:303-11. doi:10.1016/j.jhazmat.2016.05.096.

[99] Yan F, Xu K, Yao X, Li Y. Fuzzy Bayesian Network-Bow-Tie Analysis of Gas Leakage during Biomass Gasification. PLoS One 2016;11:e0160045. doi:10.1371/journal.pone.0160045.

[100] Wang D, Zhang Y, Jia X, Jiang P, Guo B. Handling Uncertainties in Fault Tree Analysis by a Hybrid Probabilistic-Possibilistic Framework. Qual Reliab Eng Int 2016;32:1137-48. doi:10.1002/qre.1821.

[101] Mohsendokht M. Risk assessment of uranium hexafluoride release from a uranium conversion facility by using a fuzzy approach. J Loss Prev Process Ind 2017;45:217-28. doi:10.1016/j.jlp.2017.01.004.

[102] Sahin B. Consistency control and expert consistency prioritization for FFTA by using extent analysis method of trapezoidal FAHP. Appl Soft Comput 2017;56:46-54. doi:10.1016/j.asoc.2017.02.027.

[103] Yazdi M, Nikfar F, Nasrabadi M. Failure probability analysis by employing fuzzy fault tree analysis. Int J Syst Assur Eng Manag 2017;8:1177-93. doi:10.1007/s13198-017-0583-y.

[104] Yazdi M. Hybrid Probabilistic Risk Assessment Using Fuzzy FTA and Fuzzy AHP in a Process Industry. J Fail Anal Prev 2017;17:756-64. doi:10.1007/s11668-017-0305-4.

[105] Yazdi M, Kabir S. A fuzzy Bayesian network approach for risk analysis in process industries. Process Saf Environ Prot 2017;111:507-19. doi:10.1016/j.psep.2017.08.015.

[106] Jiang L, Wang X. Reliability evaluation of the Chinese Train Control System Level 3 using a fuzzy approach. Proc Inst Mech Eng Part F J Rail Rapid Transit 2018;0:1-16. doi:10.1177/0954409718769193.

[107] Yazdi M, Zarei E. Uncertainty Handling in the Safety Risk Analysis: An Integrated Approach Based on Fuzzy Fault Tree Analysis. J Fail Anal Prev 2018;18:392-404. doi:10.1007/s11668-018-0421-9.

[108] Yazdi M, Korhan O, Daneshvar S. Application of fuzzy fault tree analysis based on modified fuzzy AHP 
and fuzzy TOPSIS for fire and explosion in process industry. Int J Occup Saf Ergon 2018;0:1-18. doi:10.1080/10803548.2018.1454636.

[109] Yazdi M, Soltanali H. Knowledge acquisition development in failure diagnosis analysis as an interactive approach. Int J Interact Des Manuf 2018. doi:10.1007/s12008-018-0504-6.

[110] Yazdi M. Footprint of knowledge acquisition improvement in failure diagnosis analysis. Qual Reliab Eng Int 2018:405-22. doi:10.1002/qre.2408.

[111] Yazdi M, Kabir S. Fuzzy evidence theory and Bayesian networks for process systems risk analysis. Hum Ecol Risk Assess An Int J 2018;0:1-30. doi:10.1080/10807039.2018.1493679.

[112] Yazdi M, Hafezi P, Abbassi R. A methodology for enhancing the reliability of expert system applications in probabilistic risk assessment. J Loss Prev Process Ind 2019;58:51-9. doi:10.1016/J.JLP.2019.02.001.

[113] Yazdi M, Nedjati A, Abbassi R. Fuzzy dynamic risk-based maintenance investment optimization for offshore process facilities. J Loss Prev Process Ind 2019;57:194-207. doi:10.1016/J.JLP.2018.11.014.

[114] Bedford T, Cooke RM. Probabilistic risk analysis : foundations and methods. Cambridge University Press; 2001.

[115] Ayyub BM. Elicitation of expert opinions for uncertainty and risks. CRC Press; 2001.

[116] Shafer G. A mathematical theory of evidence. Princeton University Press; 1976.

[117] Zhou D, Tang Y, Jiang W. A Modified Model of Failure Mode and Effects Analysis Based on Generalized Evidence Theory. Math Probl Eng 2016;2016. doi:10.1155/2016/4512383.

[118] Dempster AP. Upper and Lower Probabilities Induced by a Multivalued Mapping. Ann Math Stat 1967;38:325-39. doi:10.2307/2239146.

[119] Smets P, Kennes R. The transferable belief model. Artif Intell 1994;66:191-234. doi:10.1016/00043702(94)90026-4.

[120] Li Z, Xiao F, Fei L, Mahadevan S, Deng Y. An Evidential Failure Mode and Effects Analysis Using Linguistic Terms. Qual Reliab Eng Int 2016. doi:10.1002/qre.2075.

[121] Hsiao TY, Lu CN. Risk informed design refinement of a power system protection scheme. IEEE Trans Reliab 2008;57:311-21. doi:10.1109/TR.2008.920796.

[122] Yang ZL, Wang J, Bonsall S, Fang QG. Use of fuzzy evidential reasoning in maritime security assessment. Risk Anal 2009;29:95-120. doi:10.1111/j.1539-6924.2008.01158.x.

[123] Simon C, Weber P. Imprecise reliability by evidential networks. Proc Inst Mech Eng Part O J Risk Reliab 2009;223:119-31. doi:10.1243/1748006XJRR190. 
[124] Kelly DL, Smith CL. Bayesian inference in probabilistic risk assessment-The current state of the art. Reliab Eng Syst Saf 2009;94:628-43. doi:10.1016/j.ress.2008.07.002.

[125] Yang X, Rogers WJ, Mannan MS. Journal of Loss Prevention in the Process Industries Uncertainty reduction for improved mishap probability prediction : Application to level control of distillation unit. J Loss Prev Process Ind 2010;23:149-56. doi:10.1016/j.jlp.2009.07.006.

[126] Wang YF, Qin T, Li B, Sun XF, Li YL. Fire probability prediction of offshore platform based on Dynamic Bayesian Network. Ocean Eng 2017;145:112-23. doi:10.1016/j.oceaneng.2017.08.035.

[127] El-Gheriani M, Khan F, Zuo MJ. Rare Event Analysis Considering Data and Model Uncertainty. ASCEASME J Risk Uncert Engrg Sys, Part B Mech Engrg 2017;3:021008. doi:10.1115/1.4036155.

[128] Khakzad N, Khan F, Amyotte P. Safety analysis in process facilities: Comparison of fault tree and Bayesian network approaches. Reliab Eng Syst Saf 2011;96:925-32. doi:10.1016/j.ress.2011.03.012.

[129] Khakzad N, Khan F, Amyotte P. Dynamic safety analysis of process systems by mapping bow-tie into Bayesian network. Process Saf Environ Prot 2013;91:46-53. doi:10.1016/j.psep.2012.01.005.

[130] Khakzad N, Khan F, Amyotte P. Dynamic risk analysis using bow-tie approach. Reliab Eng Syst Saf 2012;104:36-44. doi:10.1016/j.ress.2012.04.003.

[131] Deyab SM, Taleb-berrouane M, Khan F, Yang M. Failure analysis of the offshore process component considering causation dependence. Process Saf Environ Prot 2018;113:220-32. doi:10.1016/j.psep.2017.10.010.

[132] Zarei E, Azadeh A, Khakzad N, Aliabadi MM, Mohammadfam I. Dynamic safety assessment of natural gas stations using Bayesian network. J Hazard Mater 2017;321:830-40. doi:10.1016/j.jhazmat.2016.09.074.

[133] Adedigba SA, Khan F, Yang M. Dynamic safety analysis of process systems using nonlinear and nonsequential accident model. Chem Eng Res Des 2016;111:169-83. doi:10.1016/j.cherd.2016.04.013.

[134] Abimbola M, Khan F, Khakzad N, Butt S. Safety and risk analysis of managed pressure drilling operation using Bayesian network. Saf Sci 2015;76:133-44. doi:10.1016/j.ssci.2015.01.010.

[135] Yuan Z, Khakzad N, Khan F, Amyotte P. Risk analysis of dust explosion scenarios using bayesian networks. Risk Anal 2015;35:278-91. doi:10.1111/risa.12283.

[136] Yuan Z, Khakzad N, Khan F, Amyotte P. Risk-based optimal safety measure allocation for dust explosions. Saf Sci 2015;74:79-92. doi:10.1016/j.ssci.2014.12.002.

[137] Abimbola M, Khan F, Khakzad N. Dynamic safety risk analysis of offshore drilling. J Loss Prev Process Ind 2014;30:74-85. doi:10.1016/j.jlp.2014.05.002.

[138] Khakzad N, Khan F, Amyotte P. Quantitative risk analysis of offshore drilling operations: A Bayesian 
approach. Saf Sci 2013;57:108-17. doi:10.1016/j.ssci.2013.01.022.

[139] Savage LJ. The foundations of statistics. Dover Publications; 1972.

[140] Von Neumann J, Morgenstern O. Theory of games and economic behavior. Princeton University Press; 2007.

[141] Hora SC. Aleatory and epistemic uncertainty in probability elicitation with an example from hazardous waste management. Reliab Eng Syst Saf 1996;54:217-23. doi:10.1016/S0951-8320(96)00077-4.

[142] Ferdous R, Khan F, Sadiq R, Amyotte P, Veitch B. Fault and Event Tree Analyses for Process Systems Risk Analysis: Uncertainty Handling Formulations. Risk Anal 2011;31:86-107. doi:10.1111/j.15396924.2010.01475.x.

[143] Ferdous R, Khan F, Sadiq R, Amyotte P, Veitch B. Handling and updating uncertain information in bow-tie analysis. J Loss Prev Process Ind 2012;25:8-19. doi:10.1016/j.jlp.2011.06.018.

[144] Ferdous R, Khan F, Sadiq R, Amyotte P, Veitch B. Analyzing system safety and risks under uncertainty using a bow-tie diagram: An innovative approach. Process Saf Environ Prot 2013;91:1-18. doi:10.1016/j.psep.2011.08.010.

[145] Martorell S, Villamizar M, Martón I, Villanueva JF, Carlos S, Sánchez AI. Evaluation of risk impact of changes to surveillance requirements addressing model and parameter uncertainties. Reliab Eng Syst Saf 2014;126:153-65. doi:10.1016/j.ress.2014.02.003.

[146] Khalil YF. Risk quantification framework of hydride-based hydrogen storage systems for light-duty vehicles. J Loss Prev Process Ind 2015;38:187-98. doi:10.1016/j.jlp.2015.09.008.

[147] Shoar S, Zarandi HR, Nasirzadeh F, Cheshmikhani E. Fast Fault Tree Analysis for Hybrid Uncertainties Using Stochastic Logic Implemented on Field-Programmable Gate Arrays: An Application in Quantitative Assessment and mitigation of Welding Defects Risk. Qual Reliab Eng Int 2017;33:1367-85. doi:10.1002/qre.2110.

[148] El-Gheriani M, Khan F, Chen D, Abbassi R. Major accident modelling using spare data. Process Saf Environ Prot 2017;106:52-9. doi:10.1016/j.psep.2016.12.004.

[149] Li X, Chen G, Jiang S, He R, Xu C, Zhu H. Developing a dynamic model for risk analysis under uncertainty: Case of third-party damage on subsea pipelines. J Loss Prev Process Ind 2018. doi:10.1016/j.jlp.2018.05.001.

[150] Hofer E. When to separate uncertainties and when not to separate. Reliab Eng Syst Saf 1996;54:113-8. doi:10.1016/S0951-8320(96)00068-3.

[151] Du YW, Wang SS, Wang YM. Group fuzzy comprehensive evaluation method under ignorance. Expert Syst 
Appl 2019;126:92-111. doi:10.1016/j.eswa.2019.02.006.

[152] Biondini F, Frangopol DM. Management, Resilience and Sustainability. n.d.

[153] Kabir S, Papadopoulos Y. Applications of Bayesian networks and Petri nets in safety, reliability, and risk assessments: A review. Saf Sci 2019; 115:154-175. doi: 10.1016/j.ssci.2019.02.009. 